Published in final edited form as:

J Policy Anal Manage. 2015 ; 34(3): 567-592. doi:10.1002/pam.21833.

\title{
Waging War on Poverty: Poverty Trends Using a Historical Supplemental Poverty Measure
}

\author{
Liana E. Fox, \\ Postdoctoral Researcher, Swedish Institute for Social Research, Stockholm University, Day \\ Phone: (+46) 7 29651655, Fax: (-46) 8 154670, liana.fox@sofi.su.se, Address: Sveavägen 164D, \\ Stockholm, Sweden 11346 \\ Christopher Wimer, \\ Research Scientist and Co-Director, Center on Poverty and Social Policy, Columbia School of \\ Social Work, Day Phone: (212) 854-0245, Fax: (212) 851-2206, cw2727@columbia.edu, \\ Address: 1255 Amsterdam Avenue, Room 735, New York, NY 10027 \\ Irwin Garfinkel, \\ Mitchell I. Ginsberg Professor of Contemporary Urban Problems and Co-Director, Columbia \\ Population Research Center, Center on Poverty and Social Policy, Columbia School of Social \\ Work, Day Phone: (212) 851-2383, Fax: (212) 851-2206, ig3@columbia.edu, Address: 1255 \\ Amsterdam Avenue, Room 714, New York, NY 10027 \\ Neeraj Kaushal, and \\ Associate Professor, Columbia School of Social Work, Day Phone: (212) 851-2385, Fax: (212) \\ 851-2286, nk464@columbia.edu, Address: 1255 Amsterdam Avenue, Room 917, New York, NY \\ 10027

\section{Jane Waldfogel} \\ Compton Foundation Centennial Professor for the Prevention of Children's and Youth Problems, \\ Columbia School of Social Work, Day Phone: (212) 851-2408, Fax: (212) 851-2206, \\ jw205@columbia.edu, Address: 1255 Amsterdam Avenue, Room 729, New York, NY 10027
}

\section{Abstract}

Using data from the Consumer Expenditure Survey and the March Current Population Survey, we provide poverty estimates for 1967 to 2012 based on a historical Supplemental Poverty Measure (SPM). During this period, poverty, as officially measured, has stagnated. However, the official poverty measure (OPM) does not account for the effect of near-cash transfers on the financial

LIANA FOX is a Postdoctoral Researcher at the Swedish Institute for Social Research at Stockholm University, SE-106 91 Stockholm, Sweden (liana.fox@ sofi.su.se).

CHRISTOPHER WIMER is a Research Scientist and Co-Director of the Center on Poverty and Social Policy at the Columbia School of Social Work, 1255 Amsterdam Avenue, Room 735, New York, NY 10027 (cw2727@ columbia.edu).

IRWIN GARFINKEL is the Mitchell I. Ginsberg Professor of Contemporary Urban Problems and Co-Director of the Center on Poverty and Social Policy at the Columbia School of Social Work, 1255 Amsterdam Avenue, Room 714, New York, NY 10027 (ig3@columbia.edu).

NEERAJ KAUSHAL is an Associate Professor at the Columbia School of Social Work, 1255 Amsterdam Avenue, Room 917, New York, NY 10027 (nk464@columbia.edu).

JANE WALDFOGEL is the Compton Foundation Centennial Professor for the Prevention of Children's and Youth Problems at the Columbia School of Social Work, 1255 Amsterdam Avenue, Room 729, New York, NY 10027 (jw205@columbia.edu).

JEL code: I32-Measurement and Analysis of Poverty 
resources available to families, an important omission since such transfers have become an increasingly important part of government anti-poverty policy. Applying the historical SPM, which does count such transfers, we find that trends in poverty have been more favorable than the OPM suggests and that government policies have played an important and growing role in reducing poverty - a role that is not evident when the OPM is used to assess poverty. We also find that government programs have played a particularly important role in alleviating child poverty and deep poverty, especially during economic downturns.

\section{Keywords}

Historical Supplemental Poverty Measure; historical poverty trends; anti-poverty policy

\section{INTRODUCTION}

The role of anti-poverty programs in the United States is controversial. In particular, ever since President Lyndon Johnson declared War on Poverty in 1964, policy analysts, journalists, and elected officials have asked, "What did it do for the poor?" (Bailey \& Danziger, 2013). Responses to this question have often come in the form of political rhetoric, with President Ronald Reagan famously asserting: "the federal government declared war on poverty, and poverty won."

Did poverty really win or did the war on poverty improve the wellbeing of the poor? To answer this question, we need to know what has been the trend in the U.S. poverty rate over the last 50 years, and whether and to what extent government tax and transfer programs have reduced poverty and for which groups. Answers to these, and related questions, are essential for informed policy debates on the importance and effectiveness of various policies in reducing poverty. However, up until now, researchers using the official poverty measure (OPM) have been unable to fully answer such questions. This is because the official measure does not capture the value of in-kind benefits (such as food stamps or housing subsidies) or tax policies (such as the Earned Income Tax Credit), both of which constitute key pillars of the United States' anti-poverty efforts. Estimates using the OPM show poverty rates about the same today as they were back in 1964-but leave unclear whether more comprehensive estimates would tell a different story.

To produce those more comprehensive estimates, this paper builds on decades of research leading up to the Census Bureau's recently developed Supplemental Poverty Measure (SPM) and extends this measure back to 1967, creating a new, comprehensive historical measure of poverty. Using our new historical SPM measure, we provide the first estimates of historical trends in poverty taking into account the full range of government anti-poverty policies. Our analyses cover the period 1967 to 2012.

The SPM came about because of widespread agreement among analysts, advocates, and policymakers that the official U.S. poverty measure is inadequate. As documented by the National Academy of Sciences (NAS) in their landmark report (Citro \& Michael, 1995), the official poverty measure (OPM) understates the extent of poverty by using thresholds that are outdated and that may not adjust appropriately for the needs of different types of 
individuals and households, in particular, families with children and the elderly. At the same time, it overstates poverty, and understates the role of government policies, by failing to take into account several important types of government benefits (in particular, the Supplemental Nutrition Assistance Program/Food Stamps and tax credits), which are not counted in cash income (Blank, 2008; Smeeding, 1977). Because of these (and other) failings, official poverty statistics do not provide an accurate picture of poverty or the role of government policies in combating poverty (Blank, 2008; Blank \& Greenberg, 2008; Hutto, Waldfogel, Kaushal, \& Garfinkel, 2011; Iceland, 2005).

Our study presents the first estimates of trends in poverty over nearly a 50-year period based on the most up-to-date thinking on how to best measure income poverty in the United States. As we mark the 50th anniversary of the War on Poverty, and with debates about antipoverty programs still raging, these trends are important to document, but the deep flaws built into the official measure currently obscure them. Using our newly developed historical Supplemental Poverty Measure, our analyses address the following questions:

1. How do trends in historical SPM poverty compare to trends in OPM poverty?

2. What role do government transfers not counted in the OPM play in reducing poverty and deep poverty?

3. What role do government programs play in reducing temporal variation in poverty and deep poverty?

4. Which government programs are most important in reducing poverty?

To briefly preview the results, we find first that historical trends in poverty have been more favorable — and government programs have played a larger role - than OPM estimates suggest. Second, government programs play a substantial and growing role in alleviating child poverty, and particularly deep child poverty—a trend that is masked by the OPM. Third, the role of government anti-poverty programs is particularly pronounced during economic downturns. Fourth, our estimates point to a particularly crucial role for the Earned Income Tax Credit and food and nutrition programs, especially in the modern era. This role is also missed by the OPM, which does not count either set of programs.

\section{BACKGROUND}

The official poverty measure (OPM) is widely criticized as being inadequate on three dimensions: 1) thresholds that do not adequately adjust for the needs of different households; 2) a measure of resources that does not include post-tax income and in-kind benefits and;3) use of incomplete family units that exclude cohabitors and unrelated children. Developing an improved poverty measure, however, is a complex undertaking and involves altering both poverty thresholds and the definition of resources necessary to meet those thresholds. The NAS panel devoted a good deal of attention to this challenge. One of the most controversial issues in setting new thresholds was whether the new measure should be absolute or relative (Burkhauser, 2009). An absolute poverty measure-such as the U.S. official poverty measure - compares a family's resources to a fixed threshold, which is only updated year-to-year based on changes in inflation. A relative poverty measure-as is used in nearly all OECD nations-compares a family's resources to a threshold that varies over 
time as living standards change, which is usually measured by trends in median income in a country.

Within-country relative measures of poverty have strong intuitive appeal, as they implicitly factor into the poverty measure the idea that an adequate amount of income in one time and place may not provide the same standard of living in a future time and place. For example, items considered luxuries in one period may be considered necessities in subsequent periods (e.g., cell phones, microwave ovens, etc.). An absolute poverty measure, on the other hand, compares resources to a poverty threshold set at a specific time and place, and updates those thresholds over time based only on changes in prices of goods and services. While absolute poverty measures can be criticized on the grounds that they fail to acknowledge that the nature of poverty within a country shifts over time, they also hold intuitive appeal for some because they provide a clear benchmark with which to assess trends in incomes over time. ${ }^{i}$

Following the NAS recommendation, the SPM is "quasi-relative" in that its thresholds increase gradually over time with consumption levels of families at the top of the bottom third of the consumption distribution, as we discuss in more detail below. Although the quasi-relative nature of the SPM measure is expected over time to lead to a higher poverty threshold, as explained below there is an offsetting demographic effect of the Census SPM measure. Furthermore, trends in poverty over time are sensitive not only to how a poverty threshold is chosen, but also what income sources and expenses are counted (Iceland, 2012).

The SPM also follows NAS recommendations for including a broader definition of resources in the measure of poverty. In particular, the official measure has long been criticized for failing to include resources stemming from near-cash or in-kind benefits like nutrition assistance programs (e.g., SNAP), housing assistance, and energy assistance. The official measure also fails to consider post-tax income, which may be increasingly important as many anti-poverty programs are now delivered through the tax system (e.g., the Earned Income Tax Credit and the Child Tax Credit). Inclusion of such resources is a critical step if one hopes to use changes in the level of poverty over time to assess how well anti-poverty programs have or have not achieved their goals. The SPM also adjusts family resources by subtracting certain "non-discretionary" expenses like medical costs, work expenses, and child care expenses from available income. While these adjustments have been more controversial (see Korenman \& Remler, 2012 for a lengthier discussion on this point), they are an attempt to reflect the fact that certain critical expenses reduce some families' ability to meet their routine needs.

Lastly, the SPM follows NAS recommendations in altering the definition of who is thought to be sharing resources within a household. While official statistics only examine the family unit—or those bound by blood, marriage, or adoption— the SPM broadens this definition to include cohabiters and their children, and some unrelated and foster children living in the

\footnotetext{
${ }^{i}$ Another advantage of an absolute measure is that relative definitions of poverty can be misleading. During recessions, a relative definition of poverty will perversely indicate that poverty has decreased if median income families are more adversely affected than low-income families, whereas an absolute measure of poverty would typically show an increase in poverty. Relative definitions of poverty also indicate increasing levels of poverty in some developing countries like China and Ireland during periods when economic growth lifted all boats and led to phenomenal reductions in absolute poverty (Blank 2008; Burkhauser, 2009; Garfinkel, Rainwater, \& Smeeding, 2010).
} 
household. As cohabitation becomes increasingly common in society, failing to take into account the fact that cohabiting couples are likely to share resources could increasingly overstate poverty in recent decades for this group.

The NAS recommendations for an improved poverty measure were used by the Census Bureau for several years to generate alternative poverty statistics on an experimental basis. They also provided the basis for state and local efforts to define poverty in a more accurate way. One of the earliest and most ambitious of these efforts was the work undertaken by Mark Levitan and colleagues at the NYC Center for Economic Opportunity, which resulted in a series of reports using an alternative poverty measure (Levitan et al., 2010; NYC Center for Economic Opportunity [CEO], 2013). Other state and local efforts followed in Wisconsin (Smeeding, Isaacs, \& Thornton, 2013), Massachusetts, Illinois, and Georgia (Wheaton, Giannarelli, Martinez-Schiferl, \& Zedlewski, 2011), California (Bohn, Danielson, Levin, Mattingly, \& Wimer, 2013), Connecticut (Zedlewski, Giannarelli, \& Wheaton, 2010) and Virginia (Cable, 2013).

The move toward an improved poverty measure took a great leap forward a few years ago with the release by the Census Bureau of poverty estimates using a new Supplemental Poverty Measure (SPM) (Short, 2011), which was developed in collaboration with the Bureau of Labor Statistics (BLS). While Census had previously released alternative poverty statistics drawing on a variety of experimental measures, this was the first time it produced figures using a single preferred alternative measure, the SPM.

These new estimates (and those in two successor reports; Short, 2012, 2013) demonstrate how using an improved measure of poverty alters our understanding of poverty and the role of government programs in reducing poverty. From the Census reports, we know that moving to the SPM results in a higher overall threshold, more resources, but also more expenses. The net effect is a slightly higher overall poverty rate-16.0 percent with the SPM vs. 15.1 percent with the OPM in 2012 - with poverty lower under the SPM than the OPM for children (18.0 percent vs. 22.3 percent) but higher under the SPM than the OPM for seniors (14.8 percent vs. 9.1 percent) (Short, 2013). The Census reports also illustrate the crucial anti-poverty role played today by programs not counted under the OPM (programs such as SNAP/Food Stamps and EITC). Because these programs offer relatively large benefits to families with children, including them in the SPM in the modern period results in lower poverty rates among children under the SPM, relative to the OPM. The OPM sets a lower threshold for seniors than for other adults under the assumption that they consume less. The SPM does not make such a distinction. In addition, for seniors, subtracting medical out-of-pocket expenditures results in substantially higher poverty rates under the SPM.

The SPM has been widely but not universally endorsed. Many analysts question its inclusion of medical out-of-pocket expenditures (an item the NAS panel failed to reach agreement on; see e.g., Korenman \& Remler, 2012). Meyer and Sullivan (2003, 2011, 2012c) note several ways in which the SPM is an improvement over the OPM, but argue that a consumptionbased measure would be superior to both the SPM and OPM. Others note, however, that a comprehensive income measure seems to perform just as well as a consumption-based measure in capturing poverty rates and trends (Bavier, 2008), while more recent trends in 
data based on consumption measures may suffer from problems in underlying consumption data (Bavier, 2014). Further, as Hoynes (2012) points out, a consumption-based measure cannot be used to produce counter-factual estimates along the lines of those we produce here.

The Census reports provide SPM estimates for 2009 to 2012 only and therefore cannot tell us how using an SPM-like measure would alter our understanding of historical trends in poverty and the role of government policies in reducing poverty over time. To address that question, we estimate an SPM-like poverty measure historically.

\section{DATA AND METHODS}

We make use of historical data from the Annual Social and Economic Supplement to the Current Population Survey (March CPS) and the Consumer Expenditure Survey (CEX) to produce historical SPM estimates for the period 1967 to 2012. We use a methodology similar to that used by the Census Bureau in producing their SPM estimates, but with adjustments for differences in available historical data. We therefore call our estimated series a historical SPM, to distinguish it from the Census Bureau's SPM. A comparison of differences in OPM, Census SPM, and the historical SPM is available in Table 1.

\section{Overview}

As detailed below, we set poverty thresholds based on consumer expenditures on food, clothing, shelter, and utilities (FCSU) between the 30th and the 36th percentiles of expenditures on FCSU, plus an additional 20 percent to account for additional necessary expenditures. Thresholds are further adjusted depending on whether the household makes a mortgage or rent payment, or if the household owns its home free and clear of a mortgage. These thresholds are based on five-year rolling averages of the CEX data when available (and on averages from fewer years when data for the previous five years are not available). ${ }^{\text {ii }}$ Thresholds are then applied to the March CPS sample using an equivalization process that weights adults and children based on standard theories of consumption and economies of scale. Rather than comparing the threshold to only pre-tax income as is done in the OPM, the threshold is compared to a much broader set of resources, including post-tax income and near-cash transfers (such as SNAP/Food Stamps), and then subtracting work, child care, and medical out-of-pocket expenditures. This process is repeated historically.

It should be noted that we use our historical SPM methodology in all years, in order to produce consistent estimates. We therefore do not switch to the Census' actual SPM in 2009 when those estimates first become available. Our thresholds and historical SPM rates for the overlapping years of 2009 to 2012 are very close to Census' actual SPM (available upon request).

\footnotetext{
ii In a related paper (Wimer, Fox, Garfinkel, Kaushal \& Walfogel, 2013a) we deviate from the Census' calculation of quasi-relative poverty thresholds and present analyses where the poverty threshold is anchored or fixed at a specific point in time. This transforms the poverty measure into an absolute poverty standard.
} 


\section{Poverty Units}

The OPM defines the "poverty unit," or those who are thought to share resources, as the family (i.e., all individuals in the household related by blood, marriage, or adoption). The SPM broadens the definition of families to include unmarried partners (and their children or family members), unrelated children under age 15 , and foster children under age 22 (when identifiable). We therefore first create SPM poverty units in the CPS in all years back to 1967 (see the appendix for details). ${ }^{\text {iii }}$ We pool all resources and non-discretionary expenses across members of the poverty unit to determine poverty status.

\section{Poverty Thresholds}

From 1984 to 2012, we follow the Bureau of Labor Statistics' SPM methodology in constructing poverty thresholds using five-year rolling averages of the Consumer Expenditure Survey (CEX) data on out-of-pocket expenditures on food, clothing, shelter and utilities (FCSU) by consumer units with exactly two children (called the "reference unit"). We adjust all expenditures by consumer units with two children by a three-parameter equivalence scale, (described in the appendix $;^{\text {iv }}$ see also Betson \& Michael, 1993) and then rank these expenditures into percentiles. We then multiply the average FCSU for the 30th to 36th percentile of FCSU expenditures by 1.2 to account for additional basic needs. We then use equivalence scales to set thresholds for all family configurations. While the BLS applies a geographic adjustment to account for varying costs of living throughout the U.S., we were unable to make this adjustment in a historically consistent manner and therefore do not include geographic adjustments. We determine thresholds overall, and by housing status. The Census Bureau produces base thresholds for three housing status groups: owners with a mortgage; owners without a mortgage; and renters. The SU portion of the FCSU is estimated separately for each housing status group.

The annual CEX series does not go back beyond 1980 except for two sets of surveys in 1960/1961 and 1972/1973. Thus, our thresholds for 1980 to 1983 are based on less than five years of data: four years of data (1980 to 1983) to construct the 1983 threshold to just a single year of data to construct the 1980 threshold. To construct thresholds in the years prior to 1980 , we follow the same methodology, but instead of using five-year averages, we estimate thresholds in 1961 and 1972/1973 and interpolate the intermediate years of 1962 to 1971 and 1974 to 1979 using the rate of change in the CPI-U. Because the 1960 portion of the 1960/1961 CEX contains only urban consumer units, we create a threshold for 1961 using just the 1961 portion of that dataset. For 1972/1973, we treat the data as we do in 1981, using both years to generate a 1973 data point.

Despite our best efforts to create a historically-consistent series, due to changes in CEX data design, our thresholds are not entirely consistent over time. In 1982/1983, the CEX was only representative of urban areas. Inclusion of these inconsistent years will affect estimates from 1982 to 1987. Additionally, the 1972/1973 CEX only includes consumer units who

\footnotetext{
iii All appendices are available at the end of this article as it appears in JPAM online. Go to the publisher's website and use the search engine to locate the article at http://www3.interscience.wiley.com/cgi-bin/jhome/34787.

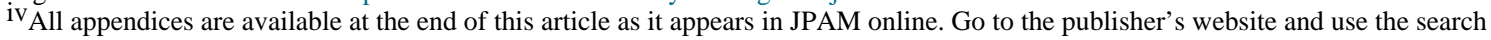
engine to locate the article at http://www3.interscience.wiley.com/cgi-bin/jhome/34787.
} 
participated in all four interviews, while in other years, all consumer units, regardless of the number of interviews they participated in, were included in the threshold estimations. Estimations of bias and corrections are discussed in the appendix. ${ }^{\mathrm{v}}$

\section{Resources}

The SPM differs from the OPM in taking into account a fuller set of resources including near-cash and in-kind benefits, as well as tax credits. We describe below how we calculate the value of these various types of resources. Especially in the very early years of available CPS data, we rely on a number of imputation approaches to estimate resources that the CPS did not ask respondents about at the time. Our imputation approach builds upon extensive previous work adapting the Census SPM to alternate datasets such as the American Community Survey, or to earlier years of the CPS when not all requisite data were available (see Betson, 2009; Hutto et al., 2011; Isaacs, Marks, Smeeding, \& Thornton, 2010; Levitan et al., 2010; NYC CEO, 2008; and Wheaton et al., 2011).

SNAP/Food Stamps-The CPS routinely measures receipt of the Supplemental Nutrition Assistance Program (SNAP), formerly known as the Food Stamp Program, beginning in 1980 (for calendar year 1979). The program, however, existed for all years included in our analysis (albeit on a very small scale in our earliest years). It grew rapidly over the 1970s as it was extended nationally, making it important to capture SNAP/Food Stamps benefits prior to 1979 in our historical SPM measure. We use a two-step procedure to impute SNAP/Food Stamps for the earlier years: each household in the CPS is first predicted to receive or not receive SNAP/Food Stamps, followed by imputation of the benefit amount for those predicted to receive SNAP. We base the procedure for imputation on administrative data on SNAP/Food Stamps caseloads and benefit levels, which we detail in the appendix.

School Lunch Program-The National School Lunch Act of 1946 launched a federallyassisted meal program that provides free or low-cost lunches to children in public and nonprofit private schools. Like SNAP/Food Stamps, however, the CPS only begins measuring participation starting in 1980 (for calendar year 1979). We impute the value of the School Lunch Program benefits using a procedure similar to SNAP/Food Stamps imputation. Details of our imputation approach are in the appendix.

Women, Infants, and Children (WIC)-The WIC program, which provides coupons that can be used to purchase healthy food by low-income pregnant women and women with infants and toddlers, was established as a pilot program in 1972 and became permanent in 1974, with large expansions occurring in the 1970s. While the CPS does not provide data on the value of WIC, since 2001 it includes data on the number of WIC recipients per household. Therefore, a procedure was necessary to impute participation in WIC prior to 2001 and the value of WIC for all years. We provide details of our imputation approach in the appendix.

\footnotetext{
${ }^{\mathrm{v}}$ All appendices are available at the end of this article as it appears in JPAM online. Go to the publisher's website and use the search engine to locate the article at http://www3.interscience.wiley.com/cgi-bin/jhome/34787.
} 
Housing Assistance-Federal housing assistance programs have existed in the United States since at least the New Deal. Such programs typically take one of two forms: reducedprice rental in public housing buildings or vouchers that provide rental assistance to lowincome families seeking housing in the rental market. In the CPS, questions asking about receipt of these two types of housing assistance exist back to 1976 (for calendar year 1975). This means housing assistance receipt for years prior to 1975 must be imputed. To estimate the value of the assistance, we first estimate rental payments as 30 percent of household income, and subtract this from the shelter portion of the threshold. We then apply a small correction factor given that this valuation will tend to overestimate the value of housing assistance relative to Census procedures, which are able to utilize rich administrative data in the modern period. Further detail on both the imputation procedure and the benefit valuation are in the appendix.

Low Income Home Energy Assistance Program (LIHEAP)—LIHEAP was first authorized in 1980 and funded in 1981. The CPS measures it starting in 1982 (for calendar year 1981). Thus, the CPS captures the entire history of the program, and no imputations were necessary for this program.

Taxes and Tax Credits-Like with SNAP/Food Stamps and the School Lunch Program, measures of after-tax income do not exist in the CPS prior to 1980 (for calendar year 1979). The government created the EITC, however, in 1975 (albeit in a much smaller form than it exists today) and the Child Tax Credit in 1997 to provide additional benefits to families with children. And income and payroll taxes have obviously existed for much longer. Thus, we must develop after-tax income measures in years prior to 1980. We used the National Bureau of Economic Research's Taxsim model (Feenberg \& Coutts, 1993) to estimate these after-tax income variables. Full details on the tax model we built are in the appendix.

\section{Non-Discretionary Expenses}

Aside from the payroll and income taxes paid generated from the tax model, the SPM also subtracts medical out-of-pocket expenses (MOOP) from income, as well as capped work and child care expenses. The CPS asks about MOOP and child care expenses directly only starting in 2010, meaning we must impute these expenses into the CPS for virtually the whole period. For consistency, we use data from the CEX to impute MOOP and child care expenses into the CPS for all years. Work expenses (e.g., commuting costs) are never directly observed in the CPS and are currently estimated based on the Survey of Income and Program Participation (SIPP). We estimate work expenses back in time to 1997 using an extended time series provided to us by the Census Bureau. For years prior to that, we used a CPI-U inflation-adjusted value of the 1997/1998 median work expenditures. We provide further details on the imputation of medical, work, and childcare expenses in the appendix. ${ }^{\mathrm{vi}}$ As the subtraction of these expenses are among the most controversial aspects of the supplemental poverty measure, we have tested the quality of our imputed values against actual values in years when both are available, and have also tested how sensitive our core

\footnotetext{
${ }^{\mathrm{vi}}$ All appendices are available at the end of this article as it appears in JPAM online. Go to the publisher's website and use the search engine to locate the article at http://www3.interscience.wiley.com/cgi-bin/jhome/34787.
} 
results are to the subtraction of our imputed expenses from available resources. When considering overlapping years between imputed and actual values from the CPS, we found that our imputed estimates of MOOP expenditures matched the distribution of actual values fairly closely, with some underestimation of expenditures at the 95th and 99th percentiles (see Appendix Table A1 for full details). vii Using our imputed values of MOOP has a minor impact on overall SPM poverty rates relative to using actual values of MOOP in these years. When we exclude the value of MOOP, work expenses, and childcare from resources, we find that this exclusion systematically lowers SPM poverty rates by about 5 percentage points, but that the long-term trends over time are unaffected, as is our understanding of the role of governmental policies and programs in reducing estimated poverty rates (results available upon request).

\section{RESULTS}

\section{Poverty Thresholds: 1967 to 2012}

Figure 1 shows the value of our estimated historical SPM poverty thresholds for 1967 to 2012 (in nominal dollars), and how they compare to the OPM thresholds for the same years, with shaded bars indicating recessions as defined by NBER. As mentioned earlier, Census and the BLS do not produce overall SPM thresholds, but only thresholds that vary by housing status. We present an overall threshold here so that we can compare the average historical SPM threshold to the OPM one. However, all historical SPM poverty rates to follow are calculated using the appropriate housing status-relevant SPM thresholds, not the overall ones.

The historical SPM and OPM thresholds track one another fairly closely over time until about 2000. Beginning in 2000 the two thresholds begin to diverge rather markedly, with the historical SPM thresholds overtaking and outpacing the OPM thresholds. By 2012, the thresholds are roughly $\$ 1,800$ apart. All else being equal, a comparison of consumption and inflation indices would lead one to expect that a threshold based on consumption (SPM) would increase more rapidly than a threshold based on inflation (OPM). It is therefore somewhat surprising how closely the historical SPM and OPM track for decades. However, basing the thresholds on a reference unit of all two-child families tempers the growth in historical SPM thresholds due to demographic changes in the composition of two-child families that have increasingly become less affluent and have shifted to include more single parents who have lower incomes. Up to about 2000, demographic changes almost completely offset the expected growth in the threshold that comes from the quasi-relative nature of the SPM measure. The thresholds diverge in the 2000s because the growth in living standards exceeds the offsetting demographic effect.

It may seem at first a bit of a puzzle that the historical SPM thresholds do not come down during the Great Recession. However, it is worth remembering that the historical SPM thresholds are based on five years of data, meaning the point estimate for, say, 2009, is based on data from 2005 to 2009, and thus will include two to three years of the housing

\footnotetext{
${ }^{\text {vii }}$ All appendices are available at the end of this article as it appears in JPAM online. Go to the publisher's website and use the search engine to locate the article at http://www3.interscience.wiley.com/cgi-bin/jhome/34787.
} 
bubble that preceded the Great Recession. It is also possible that because the components of the SPM thresholds (food, clothing, shelter, and utilities) are a basic bundle of "necessities," they may be less susceptible to large economic shocks than overall spending would be.

Nevertheless, it will be illuminating to watch trends in the SPM thresholds in coming years, when the five-year moving averages will be more heavily dominated by the years of the Great Recession and its aftermath.

\section{Historical SPM versus OPM Poverty Rates}

Figure 2 presents our overall time series of historical SPM and OPM poverty rates. In the aggregate, our estimated historical SPM poverty rates are consistently higher than the OPM rates, although generally the difference is small, roughly 1 to 5 percentage points. This figure shows that historical trends in poverty have been more favorable than the OPM estimates show, with poverty declining over time. Here and elsewhere, it is important to note that we are not able to test the precision of the differences in estimates, due to the uncertainty introduced by the extensive imputations we carry out.

In 1967, the historical SPM poverty rate is 4.8 percentage points higher than the OPM rate and the gap narrows over time, especially during the late 1990s when the gap shrinks to about a half a percentage point. The gap appears largest in the early part of the time series, which makes sense given that the in-kind benefits added to resources during this time period are still very small, while other major differences embedded in the historical SPM (subtraction of income and payroll taxes, work expenses, and medical expenses) have the net effect of increasing poverty rates. After 2000, as the historical SPM thresholds begin to pull away from the OPM thresholds and following the recession of the early 2000s, the historical SPM and OPM poverty rates begin to diverge again. By 2012, the historical SPM poverty rate is only 1 percentage point higher than the OPM rate.

The Role of Government Programs in Reducing Poverty-In this section, we make use of the historical SPM to calculate a set of counterfactual estimates for what poverty rates would look like if we did not take government transfers into account. We note that these counterfactual estimates tell us in an accounting sense how much taking government transfers into account alters our estimates of poverty. Because we do not model potential behavioral responses to the programs, these estimates cannot tell us what actual poverty rates would be in the absence of the programs. However, in a detailed and exhaustive study of means-tested and social insurance programs in the U.S., Ben-Shalom, Moffitt, and Scholz (2011) document that while many programs have behavioral effects, their aggregate effect is tiny and does not affect the magnitude of their anti-poverty impact. Earlier studies based on historical data have reached similar conclusions (see Danziger, Haveman, \& Plotnick, 1981; Moffitt, 1992 for a review of the earlier literature).

We begin by constructing three resource measures, total SPM resources, SPM resources minus SPM transfers, and SPM resources minus all government transfers. SPM transfers include: food and nutrition programs (SNAP/Food Stamps, School Lunch, WIC); housing subsidies, EITC, LIHEAP and stimulus payments. All transfers include: SPM transfers plus cash welfare and social insurance programs (Social Security, Unemployment Insurance, 
Worker's Compensation, Veteran's Payments, and government pensions). ${ }^{\text {viii }}$ While the Child Tax Credit is included in total after-tax income, the CPS does not separately identify it prior to 2005, so it is not included in either of the transfer counterfactual categories.

Figure 3 shows the difference that including transfer payments makes in reducing poverty by showing the percentage point reduction in poverty documented in the historical SPM vs. OPM estimates. While both measures show that the role of governmental transfers in reducing poverty has grown over time, the OPM estimates increasingly understate the percentage point reduction in poverty associated with these transfers. Figure 3 indicates that the role of government transfers grew from reducing the poverty rate by less than 6 percentage points in 1967 to nearly 15 percentage points in 2012. The OPM estimates would capture most of this in 1967 (5 out of 6 percentage points) but would capture a lesser portion in 2012 (9 out of 15 percentage points). This is because most government transfers were cash-based in the 1960s, and thus captured in the OPM. But today in-kind and post-tax transfers are much more important, and their role is missed in the OPM, which does not count them as part of families' resources.

We next examine the role of including transfer programs for overall poverty. Figure 4a shows poverty rates under the historical SPM and then-in the counterfactual scenariosunder the historical SPM but without key government transfers. We also show the distinct effect of including the transfer programs newly counted under the SPM. Without including the programs newly counted under the SPM (which includes: SNAP, housing subsidies, school lunch, energy subsidies, WIC, EITC and stimulus payments), overall poverty rates would be 4.4 percentage points higher in 2012-20.4 percent vs. 16.0 percent. Examining the counterfactual without all government programs (SPM transfers plus welfare, SSI, Social Security and unemployment insurance), poverty would be nearly twice as high in 201230.5 percent vs. 16.0 percent. In other words, including all government programs in the resource measure cuts the poverty rate in half in 2012 (from 31 to 16 percent), while the inclusion in 1967 only cuts poverty by a quarter (from 25 to 19 percent), highlighting the substantial and growing role of governmental programs in alleviating poverty.

Figure $4 \mathrm{~b}$ shows the effect of including government transfers for deep poverty (the share of individuals with incomes below 50 percent of the poverty threshold). In 2012, we estimate the deep poverty rate under the historical SPM to be only 5.3 percent, while, if no transfers were included, the deep poverty rate would be 19.2 percent—over 3 times higher.

The second striking finding that emerges from Figures $4 \mathrm{a}$ and $4 \mathrm{~b}$ is the extent to which government transfers seem to mute temporal variation in poverty rates, especially deep poverty rates. Without including government transfers the poverty and deep poverty rates would have climbed and fallen during and after the early 1980s recessions, the early 1990s recession, the early 2000s recession, and, most recently, the Great Recession, as evidenced by the shaded recession bars. Contrast that with the SPM deep poverty rate trend, which takes the full array of transfers into account and never shows deep poverty exceeding 6.1

\footnotetext{
viii Government pensions are only included in the series from 1967 to 1974 . After that they are not separately identifiable from other retirement income in the CPS.
} 
percent, and generally hovers between 4 and 6 percent. This buffering effect is somewhat less evident in the overall poverty rate, but even here the rise and fall in poverty rates over time is less dramatic after including transfers than before. Estimates from the OPM would miss much of this poverty reduction (as seen in Figure 3).

\section{Historical SPM Results for Children}

Many of the transfer programs (SNAP/Food Stamps, EITC, WIC, and School Meals) newly captured by the historical SPM explicitly target families with children or have much more monetary value for families with children than for other households. As such, in this section we present historical trends in poverty rates for children, as well as counterfactual analyses of the role of including government programs in reducing child poverty.

Figure 5 shows the OPM and historical SPM poverty rates for children. Census' SPM analyses show that in the past few years, the child poverty rate under the SPM is lower than under the OPM because the former counts many more benefits for families with children (Short, 2013). But Figure 5 shows that this has not always been the case. Prior to the 1990s, historical SPM child poverty rates are typically higher than corresponding OPM rates. This points to the potential growing importance of antipoverty programs targeted at families with children, especially programs not counted in official poverty statistics, a point to which we now turn.

\section{The Role of Including Government Programs in Reducing Child Poverty-}

Figure 6a shows the role of transfer programs for child poverty. As shown in Figure 6a, including the SPM transfers in the poverty measure makes a substantial, and growing, difference in estimating child poverty rates. Absent the programs newly counted under the SPM, child poverty rates would be over 8.7 percentage points higher in 2012-27.3 percent vs. 18.6 percent. And absent all government programs, child poverty would be 12 percentage points higher in 2012-30.6 percent vs. 18.6 percent. In both cases, these effects on poverty rates grow over time. For example, including all transfers reduced child poverty rates by just under 3.5 percentage points in 1967, but this anti-poverty effect grew steadily to about 8 percentage points in the 1970s and early 1980s. Prior to the Great Recession, the effect of transfers on child poverty rates peaked at about 10 percentage points in the mid-1990s before reaching record highs in the past few years. Likewise, the effect of including the package of transfers newly counted in the SPM steadily increased over time, from just under 1 percentage point in 1967 to nearly 9 percentage points in the past few years.

Figure $6 \mathrm{a}$ also highlights the high degree of volatility in the child poverty rate that coincides with the business cycle. While including the value of all SPM transfers results in a slightly muted increase in child poverty rates during recent recessions relative to their increase without transfers, it is still notable to see the increase in child poverty rates during the recessions in the 1980s. From this figure it appears that government policies and programs have been more effective in smoothing poverty rates during recessions in recent years than in the past. 
Figure $6 \mathrm{~b}$ shows the effect of including government transfers for deep child poverty rates. It is remarkable how flat the historical SPM deep poverty rate for children is, relative to what deep poverty rates would be absent accounting for safety net transfers. Figures $6 \mathrm{a}$ and $6 \mathrm{~b}$ demonstrate how including transfers helps protect children from the consequences of the business cycle, keeping deep poverty relatively low and steady in the face of changes based solely on families' market incomes. In 2012, in the wake of the Great Recession, deep poverty would be nearly 11 percentage points higher for children-16.4 percent vs. 5.4 percent-absent government transfers. The important role of government in protecting vulnerable children and families from fluctuations in the business cycle is highlighted in this figure, but would be missing from an analysis using the OPM.

One of the motivating forces behind the creation of the SPM was that the OPM does not count after-tax income. Tax credits as an anti-poverty program became increasingly important for many low-income families after the expansions of the EITC in the early 1990s (Grogger 2004; Hoynes, 2009). At the same time, cash welfare-which is captured in the OPM — began to play a less important role, as federal welfare reform in 1996 time-limited the program and added work requirements, subsequent to which caseloads dropped precipitously (Blank, 2002). And as cash welfare dropped in importance in recent years, enrollment in nutrition assistance programs like SNAP have expanded dramatically (Ganong \& Liebman, 2013).

In Figure 7, we juxtapose trends in the historical SPM poverty rate absent cash welfare benefits and absent the EITC and nutrition programs relative to the actual historical SPM poverty rate and the historical SPM deep poverty rate. We focus here on child poverty, as these programs are largely targeted at families with children. Three things become evident from Figure 7. First, cash welfare used to play a substantial role in reducing child poverty in America. In the 1970s and 1980s, for instance, including the AFDC program reduced estimated child poverty rates by approximately 2 percentage points. But after 1996, welfare's effect on poverty rates dissipates very quickly, to the point where in the current period including the program reduces child poverty rates by only about one half of a percentage point. Second, the EITC and nutrition programs have become increasingly important, reducing estimated child poverty rates by 8 percentage points in 2012, playing a much larger role in poverty-reduction than cash welfare did at its peak. The role of tax credits would be even larger if we were able to include the CTC alongside the EITC in our estimates. ${ }^{\text {ix }}$ Figure 7 thus illustrates how, in the wake of welfare reform, the importance of cash welfare (which is counted in the official poverty measure) has diminished, while the importance of tax credits and nutrition programs (which are not counted) has grown tremendously.

Figure 7 also shows that including cash welfare programs targeted at very low-income families once made a substantial difference in reducing deep poverty rates among children. The deep poverty lines in Figure 7 again show the declining importance of cash welfare, and

\footnotetext{
ix In separate analyses (not shown, available on request) we show that the net effect of the tax system historically was to increase poverty rates, whereas after the reforms of the 1990s the net effect of the tax system reversed and now decreases poverty rates. This, again, speaks to the growing important of tax credits as antipoverty policy.
} 
the growing importance of the EITC and nutrition programs. But, in contrast to the trends for poverty, we see very similar effects of the TANF/AFDC program at its peak (reducing deep child poverty rates by 5.3 percentage points in 1983-1984) as EITC and nutrition programs at their peak (reducing deep child poverty rates by 5.7 percentage points in 2012).

\section{Historical SPM Results for Elderly}

Figure 8 provides another interesting story masked by the overall trends. For the elderly, the OPM and historical SPM poverty rates both plummet in the 1970s, which probably reflects the expansions of the Social Security program that occurred, starting in the early 1970s (Englehardt \& Gruber, 2006). But while the OPM poverty rate for the elderly continues drifting downward after 1980, the historical SPM poverty rate for the elderly first levels off and then begins rising after 2001. As mentioned, the SPM subtracts medical out-of-pocket (MOOP) expenses from resources, a decision that is especially consequential for elderly poverty rates. So, if medical care is getting more expensive over this period, then that could explain the fanning out of elderly historical SPM and OPM rates we see in Figure 8.

However, supplemental analyses revealed that this was only partially the case. In addition to increasing MOOP expenses, two other factors combined to explain the divergence we see starting in the 1980s: the relative decline in the share of the elderly who own their home without a mortgage (and thus face a lower poverty threshold); and the general increase in the historical SPM poverty thresholds in the 2000s. Many elderly individuals have incomes that hover just above the OPM threshold, so the combination of gradually higher thresholds, as well as the subtraction of medical expenses, results in the fanning out of the historical SPM vs. OPM elderly poverty rates in Figure 8.

\section{LIMITATIONS}

Our study has several important limitations. First, any attempt to construct a poverty measure as technically complex as a historical SPM must rely fairly heavily on imputation procedures. Many of the data components of the SPM are simply not measured historically in the Current Population Survey, the dataset used to estimate domestic poverty rates. Medical expenses and mortgage status, for instance, are not collected until 2010, while SNAP is unavailable prior to 1980 and housing subsidy receipt prior to 1976. As such, there is some inherent uncertainty built into our results. Despite this uncertainty, many of the programs that require imputing were still fairly small during the time period for which we must impute. Further, our main conclusions remain even if we ignore components of the SPM that must be imputed for essentially the entire time series-e.g., MOOP, work and childcare expenses (details in the appendix). ${ }^{\mathrm{x}}$ However, an important limitation remains as we do not construct standard errors due to the complexity of our imputations, so formal tests for statistical significance cannot be conducted with our data. This is an important area for future research.

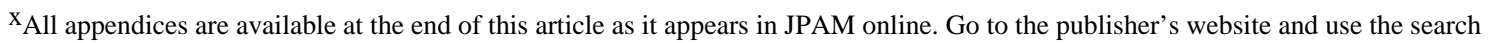
engine to locate the article at http://www3.interscience.wiley.com/cgi-bin/jhome/34787.
} 
A second limitation is that we are not currently able to adjust our historical SPM poverty thresholds geographically for the cost of living (or, more specifically, the cost of rents in different metro areas). This remains an important area for future research, and will be critical for state-level historical SPM rates or national trends for different key subgroups (e.g., immigrants), whose poverty rates may be sensitive to geographical context. We know in the current period, however, that geographic adjustment of the poverty thresholds makes little difference for the overall national poverty level estimated under the SPM. It remains to be seen if this is true historically.

Another limitation with the current estimates relates to the treatment of taxes. For both the pre-1980 period where we use Taxsim and the post-1980 period where we use Census variables, after-tax income is calculated using a tax calculator. Reliance on tax calculators leads to the assumption that everyone eligible for certain tax credits, such as the EITC, actually claim them, a fact that we know to be untrue in the real world (Short, Donohue, \& Lynch, 2012). Our estimates, and also the Census', are likely then to overstate the role of tax credits like the EITC. Given the well-documented underreporting of other benefits (e.g., Meyer, Mok, \& Sullivan, 2009), however, we are unlikely to be overstating the impact of all government transfers. Indeed, an important issue not addressed in our work here is the problem of the under-reporting of benefits in the March CPS; to the extent that benefits are under-reported, and such under-reporting has grown over time (Wheaton, 2008), this will lead us to under-estimate the role of government policies, and more so over time. Meyer and Sullivan (2012a, 2012b) argue that such under-reporting is one reason why consumptionbased estimates show more reduction in poverty over time than do income-based ones, though others argue that this is not the only reason (Bavier, 2014).

Another limitation has to do with limited CEX data in early years. Beginning in 1984, our thresholds are based on five-year moving averages of expenditures, but prior to 1980 we only have two data points to interpolate intermediate thresholds, 1960/1961 and 1972/1973. While these thresholds are consistent with later trends, there is a greater potential for bias in these earlier estimates, due to the lack of a consistent time series on consumer expenditures in the earlier period of our analyses.

As acknowledged earlier, our analyses of counterfactuals do not take into account potential behavioral responses to safety-net programs. More generally, our estimates illustrate how taking particular government programs into account alters estimates of poverty, but cannot provide proof of the causal role played by particular programs. In line with the SPM methodology, we subtract medical and other non-discretionary expenses from income. But this treatment of medical out-of-pocket expenditures remains controversial (see e.g., Korenman \& Remler, 2012; Meyer \& Sullivan, 2012a), and future research should explore alternative treatments of such expenses in the context of poverty measurement. We did find that our core results related to overall trends in poverty and the role of government policies and programs were not sensitive to the exclusion of these expenses from available income, though they, of course, affect levels in any given year.

Finally, it is useful to recall that both the OPM and SPM are income-based poverty measures and, as such, capture only one dimension of disadvantage. There continues to be a need for 
further development and research on measures that capture income poverty alongside disadvantage in terms of other dimensions, such as wealth, material hardship and well-being, and social exclusion (Nolan \& Wealan, 2010; Smeeding, 2009; Wimer et al., 2013b).

\section{CONCLUSION}

As we mark the 50th anniversary of the War on Poverty, the overall poverty rate, at first glance, appears to be much the same today as it was back then. Under the OPM, overall poverty was 14 percent in 1967 and 15 percent in 2012. Even under the improved historical SPM, overall poverty is not much lower today than it was back then-down from 19 percent to 16 percent. Does this mean that the War on Poverty has had little or no effect on poverty?

To answer this question, we need to know the counterfactual: what poverty rates would be today, in the absence of government anti-poverty programs. Producing this counterfactual is challenging, since it would require estimating behavioral models of how individuals and families would respond if government programs did not exist. In this paper, we have a more modest goal: to provide an accounting of the poverty rates that would exist if we did not take into account the full range of benefits families receive from government programs.

Our estimates are similar to the "zeroing out" exercise undertaken by Bitler and Hoynes (2013) in their analysis of the role of the safety net in the Great Recession. Our analysis differs from theirs in using a historical SPM, whereas they use an SPM-like measure of income alongside OPM thresholds. The time period also differs-their focus is 1980 to the present whereas our analysis goes back to 1967. Meyer and Sullivan (2012a, 2012b) reach a similar conclusion in their historical analysis using a consumption-based measure of poverty. Although their methodology differs from ours, they also find that the OPM time series understates progress in reducing poverty since the War on Poverty.

Our analysis has four main findings. First, we find that historical trends in poverty have been more favorable — and that government programs have played a larger role — than OPM estimates suggest. The OPM shows the overall poverty rates to be nearly the same in 1967 and 2012-at 14 and 15 percent respectively. But our counterfactual estimates using a historical SPM tell a different story. In 1967, the historical SPM poverty rate was 19 percent, and without government programs would have been 25 percent. In 2012, the historical SPM poverty rate was 16 percent, and without government programs would have been 31 percent. In other words, including government programs in the resource measures today cuts poverty estimates nearly in half (from 31 percent to 16 percent) while in 1967 they cut poverty by only a quarter (from 25 percent to 19 percent).

Second, government programs play a substantial and growing role in alleviating overall poverty and child poverty, and particularly deep poverty - a role that would be masked in estimates using the OPM. Taken together, including government programs in the resource measure in 2012 reduced overall poverty estimates by 14.5 percentage points, deep poverty by 14 percentage points, child poverty by 12 percentage points, and deep child poverty by 11 percentage points, all much larger than comparable estimates in 1967. Estimates from the OPM would miss much of this poverty reduction, particularly among children and in the 
modern period when cash welfare plays a smaller role. However, our estimates also reinforce the conclusion that policy could play a greater role in protecting children from poverty (see e.g., Hahn, Isaacs, Rennae, Steuerle, \& Vericker, 2011; Smeeding \& Waldfogel, 2010). Our historical SPM results confirm the dramatic decline in poverty for the elderly since the War on Poverty associated with expansions in Social Security, although they also reveal continuing challenges for this group.

Third, the role of government anti-poverty programs is particularly pronounced during economic downturns-meaning these programs play an important role in protecting individuals and families from the vagaries of the economic cycle. Without including government programs, deep child poverty rates would be as high as 20 percent during economic downturns in recent history, as opposed to the 4 to 6 percent rates we observe with government programs. Again, this role is missed in the OPM estimates. This finding highlights the important role governmental policies and programs can play in alleviating poverty, especially among children, during economic downturns.

Finally, by using a historical SPM that takes into account the full array of government antipoverty programs, we are able to quantify the role of different types of programs. Our estimates point to a particularly crucial role for tax credits and food and nutrition programs, especially in the modern era. In 2012, including the EITC and nutrition programs reduced child poverty rates by approximately 8 percentage points, up from less than one percentage point in 1967. Again, this role would be missed by the OPM, which does not count the value of either set of programs.

Better measurement leads to our conclusion that government anti-poverty programs have been more successful in reducing poverty than was previously thought. While poverty rates remain troublingly high even under an improved measure of poverty, our results underscore the critical importance of proper measurement for understanding how policy interventions have or have not affected the long-term trajectory of poverty in the United States. Looking ahead, perhaps this finding will prove to be an antidote to the increasingly widespread view that government anti-poverty policies are ineffective. Our results show that, with a more accurate measure, the role of government policies is considerably more positive than commonly thought. However, our results also show that child poverty-in particular, before government transfers are taken into account—remains stubbornly high. This latter finding suggests an important role for a broader set of anti-poverty policies such as the minimum wage and other supports for working parents.

\section{Acknowledgments}

We are grateful for funding support from the Annie E. Casey Foundation and from the National Institute of Child Health and Human Development (NICHD) through grant R24 HD058486-03 to the Columbia Population Research Center (CPRC). We benefited from research assistance from Madeleine Gelblum, Nathan Hutto, JaeHyun Nam, and Ethan Raker. We are also grateful to seminar participants at CPRC and Russell Sage Foundation, as well as many colleagues who provided helpful insights and advice, in particular, Jodie Allen, Ajay Chaudry, Sheldon Danziger, Daniel Feenberg, Gordon Fisher, Thesia Garner, Charles Hokayem, David Johnson, Mark Levitan, Laryssa Mykyta, Trudi Renwick, Kathy Short, and Tim Smeeding. 


\section{APPENDIX}

This appendix provides more detail about the methods used to construct our historical SPM series.

\section{Poverty Units}

Unmarried partners are directly identified in the CPS since 1995, so for years prior to that we must seek to identify them through other means. We use the well-established adjustedPOSSLQ routine (which stands for Persons of the Opposite Sex Sharing Living Quarters). We follow Casper, Cohen and Simmons (1999), who define an adjusted POSSLQ household as one that meets the following criteria: two unrelated adults (age 15+) of the opposite sex living together, with no other adults except relatives and foster children of the reference person, or children of unrelated subfamilies.

Prior to 1988, it is not possible to identify foster children in the CPS (and instead they are coded as unrelated individuals), so foster children between the ages of 15 and 22 are excluded from SPM family units from 1967 to 1987.

After 2007, detailed relationship codes make it possible to identify both biological parents of a child in a household even if these individuals do not claim to be unmarried partners. However, prior to 2007, these detailed relationship codes are not available, so we must rely on relationship codes of individuals in reference to household head or family reference person. Prior to 1975 , only relationship to household head exists, not relationship to family head.

\section{Thresholds}

Despite our best efforts to create a historically consistent series, due to changes in CEX data design, our thresholds are not entirely consistent over time. In 1982/83, the CEX was only representative of urban areas. Inclusion of these inconsistent years will affect estimates from 1982 to 1987 . However, based on an analysis (not shown) of 1980 to 1991 data, we find that urban-only thresholds differ from the full thresholds by between 4 to 6 percent. We believe the magnitude of bias in our 1982 to 1987 thresholds to be small based on these results, which provide an upper-bound on the bias in our thresholds from using urban-only estimates for 1982/83, as actual estimates would use five-year averages, including years with rural samples as well. Additionally, the 1972/73 CEX only includes consumer units who participated in all four interviews, while in other years, all consumer units, regardless of the number of interviews they participated in, were included in the threshold estimations. Thus, our thresholds will be affected by any systematic attrition. To estimate the potential magnitude of this bias, we estimated thresholds for 1980 to 1985 , restricting the sample to units who participated in all four interviews, and found the threshold for non-attritors to be approximately 3 percent higher than the threshold for the full sample, which increased the SPM rate by 0.7 percentage points. To account for the potential bias incurred by using the 1972/1973 sample, which only contains non-attritors, we downwardly adjust our thresholds obtained from these years by 3 percent. 


\section{Equivalence Scale}

We follow the Census Bureau in using a three-parameter equivalence scale to adjust poverty thresholds for poverty-unit size and composition. This equivalence scale is as follows:

Families without children: Equivalence scale $=(\text { adults })^{0.5}$

Single parents: Equivalence scale $=(\text { adults }+0.8 * \text { first child }+0.5 * \text { other children })^{0.7}$

All other families: Equivalence scale $=(\text { adults }+0.5 * \text { children })^{0.7}$

\section{Geographic Adjustment}

The SPM adjusts poverty thresholds for geographic differences in the cost of housing. Specifically, they use five-year American Community Survey data on rental payments in metropolitan areas to adjust the shelter and utilities component of the SPM poverty thresholds. In contrast, our historical-SPM estimates do not yet adjust poverty thresholds for geographic differences in cost-of-living, given the paucity of consistent data back to 1967 necessary to implement geographic adjustments. Developing a method of implementing a consistent geographic adjustment over time remains an important area for future research. For more on geographic adjustment under the SPM, see Renwick (2011).

\section{Mortgage Status}

Data for constructing thresholds by housing status are not consistently available for all years. From 1976 to 2008, the CPS asks respondents whether they owned or rented their dwelling, but not about their mortgage status; since 2009, a question on this item has been included. There are no housing tenure questions in the CPS prior to 1976.

To follow the Census SPM methodology, which requires thresholds based on three housing status groups, we imputed mortgage status from the CEX to the CPS in 1980 to 2012 and in 1972/1973. This imputation included poverty status, age, race, education and marital status of household head, family size and region as well as interactions between race and education and interactions between race and age. This imputation equation is re-estimated for each year, allowing the relationship to vary over time. For the intermediate years 1974 through 1979 the coefficients were linearly interpolated and applied to CPS data to estimate predicted likelihoods of having a mortgage among homeowners. For 1967 through 1971, the same annual rate of change in the relationships between 1972/1973 and 1980 was assumed and extrapolated to the earlier years.

Prior to 1974, a two-step imputation process was applied, first, to determine ownership vs. renter status and, second, to determine mortgage status among owners. The first imputation included the same covariates as the mortgage status imputation described above but also included deciles of income and welfare recipiency. The incidence rate of ownership was constrained to match the incidence in the CEX.

Applying the housing mortgage imputation to 2010 to 2012 (years where we have actual values), we correctly predict mortgage status for 75 percent of households in 2010 to 2012. Similarly, our two-step imputation process correctly predicts home ownership in 76 percent 
of households in 1975 through 1979. Using actual versus imputed mortgage status only changes the SPM rate by 0.2 percentage points in 2010 to 2012, while using imputed home ownership changes SPM by 1.0 percentage point in 1975 to 1979. Imputed mortgage status is used in all years, even from 2010 to 2012 where we have actual mortgage status. This is done to avoid a break in the series and to be consistent with our treatment of MOOP, child care and work expenses.

\section{SNAP}

To impute SNAP benefits into the CPS for years prior to 1979, we first impute receipt of benefits to household heads or primary individuals (which we jointly call "heads"). To accomplish this, we first estimated the percent of heads in 1980 who reported receiving food stamps in 1979. We then harnessed administrative data on caseloads published by the USDA. The USDA provides annual caseloads (average monthly caseloads for a given year) for every year back to 1969 . We were able to add caseloads back to 1967 using data from the Statistical Abstract(s) of the United States to create a consistent time series across the entire period. We then took the estimated percent of heads receiving food stamps in 1979, and estimated the same percent for prior years using rate of change in the caseload after adjusting for overall population growth. This estimated percent of heads receiving food stamps then served effectively as the percentage of heads we would constrain our imputation to. It should be noted that SNAP receipt is underreported in the CPS, so that by taking the percentage of reported receipt in the 1980 CPS and deflating it backwards historically using changes in the caseload, our imputation procedure produces similarly underreported estimates of SNAP in earlier years, so that no break will appear in trend lines starting when SNAP receipt is self-reported. This is also true for our other imputations.

The basic method for deciding to whom to assign SNAP receipt in a given year of the CPS was to run a linear probability model within the 1972/1973 Consumer Expenditure Survey predicting receipt of food stamps among consumer unit heads. The factors used to predict SNAP receipts were: receipt of public assistance/welfare, number of children, unemployment status, a dummy for having one adult in the family, a dummy for having 3 or more adults in the family, age categories, education categories, race, family size, a dummy for being married, and race, times education interaction terms. We then computed the predicted probability of receiving food stamps from this model, and used the same covariates from that model in a given year of the CPS to impute CPS heads' probability of receiving food stamps. The constraint factor was then used to determine the cutoff for assigning SNAP receipt. For example, if we estimated that 6 percent of heads in the CPS should be receiving food stamps in a given year, we would assign the 6 percent of CPS heads with the highest predicted probability of receiving food stamps as the group for whom we impute a benefit.

The next step in our imputation process is to actually assign a value to the food stamps received. It is worth noting that in the 1970s, the Food Stamp Program still had a "purchase requirement," which, depending on your income, would dictate how much a family would have to pay for, say, $\$ 100$ worth of food stamps. So the value of the benefit in the 1970 s is the difference between the total value of the benefit and the amount families are required to 
spend in order to purchase that total value. This is called the "bonus value," and it is the amount we attempted to impute to recipients. To accomplish this, we used a hot-deck procedure based on poverty status, receipt of other public assistance, number of children, and number of adults. We cross-classified these variables into 36 mutually exclusive groups, and found ten deciles of bonus values within each group. We find the same mutually exclusive groups in the CPS for a given year, and within these groups we randomly assign people to the decile values established for their group in the CEX. Since the CEX is from 1972/1973, we then updated estimated imputed values for inflation using the CPI-U. This estimated benefit value was then assigned to everyone else in the heads' SPM unit. To bring values up from 1972/1973 to, say, 1976, we inflate the imputed values by the ratio of the average benefit level in 1976 to the average benefit level in 1972/1973 (an average of those two years' average benefit levels).

\section{School Lunch Program}

Our approach for imputing participation in the school lunch program is largely similar to our imputation of SNAP, and included the same set of predictors. Because no information exists on this program in the 1972/1973 CEX, however, our dataset used for imputation is the 1980 CPS. As with SNAP, we constrain the percentage of heads down (or up) each preceding year, scaled by changes in the administrative caseload. The administrative data here come from the USDA and were compiled back to 1969 by Robert Moffitt and his colleagues. We extended the series back to 1955 using information from the Statistical Abstracts of the United States. To assign monetary values to those for whom we impute benefit receipt, we use the same model but predicting the 1979/1980 family value of school lunch calculated by the Census. We then deflate this benefit by the CPI-U.

\section{WIC}

Our procedure for imputing WIC benefits into the CPS is a two-step procedure. First, for years prior to 2001, we imputed WIC incidence at the household level. Second, we calculate the benefit value for all years using administrative data on average per person WIC expenditures (see: http://www.fns.usda.gov/pd/wisummary.htm).

\section{WIC Incidence}

From 2001 onwards, the number of WIC recipients per household was reported in the CPS. However, as nearly all families (>95 percent) who reported receiving WIC, only reported receiving it for a single family member, we only impute a yes/no incidence instead of the number of recipients per household. To estimate incidence, we first identified all families currently automatically income-eligible for WIC: those currently receiving food stamps, public assistance or Medicaid, with at least one child age five or below. While WIC is also available for pregnant women without children, we have no way of identifying pregnant women in the CPS. WIC also has a nutrition risk requirement for eligibility based on medical/nutritional guidelines that we cannot observe in the CPS, so some income eligible families would likely be nutritionally ineligible, but we cannot distinguish between these families in the CPS. 
To constrain the number of recipients, we first estimate the share of WIC income-eligible families from the CPS to administrative participation data for 2001 to 2010 and then constrain the number of recipients in earlier years to match this ratio. We use OLS regression to estimate the likelihood of WIC receipt among income-eligible families, based on number of eligible kids, household income, and poverty status. While WIC was permanently established in 1974 , only a small number $(88,000)$ of individuals participated. As a result, we do not believe we can accurately identify recipients in this year and estimate WIC beginning in 1975.

\section{WIC Value}

We calculate WIC value by multiplying the average annual WIC food costs per person (based on monthly USDA administrative costs*12 from http://www.fns.usda.gov/pd/ wisummary.htm) by the number of recipients per household (which is 0 to 4 from 2001 to 2012 and 0 to 1 prior to 2001). This value is then divided evenly among household members and summed for SPM family units.

\section{Housing Assistance}

Our imputation model for receiving housing assistance is largely similar to that for SNAP and school lunch, though here we predict for renting heads. The administrative data are also somewhat different. We begin with a time series produced by Robert Moffitt and colleagues and taken from HUD data that show total households receiving direct housing assistance administered by HUD. This series, however, only exists back to 1977. So we take a second series, total outlays for discretionary housing assistance, which we were able to extend back to 1962 (Moffitt's tables go back to 1970). The source of the data is the same as Moffitt's: White House historical budget tables. When expressed in constant dollars and compared against the total number of households receiving direct housing assistance, however, we find that the cost per household rose substantially over time between 1977 and the present. This may be because the universe of what is covered under all discretionary housing assistance is larger and changes over time, relative to the number of units assisted under low-income housing assistance programs like public housing and Section 8 . Nevertheless, this makes it difficult to know how best to "back out" the number of households receiving assistance for years prior to 1977, which is the administrative data series we would ideally want. The trend in "cost per household," however, between 1977 and the present (2009) was roughly linear, however. We assume that this trend would extend back in time between 1967 and 1977. So, with the total dollars spent and our estimate of the number of dollars per household, we are able to divide out and reach an estimate of the total number of households assisted. We then use this to constrain the percentage of households to which we assign subsidy receipt from the imputation model.

The Census values housing assistance by taking the lesser of (a) the shelter portion of the threshold minus estimated rental payments, or (b) the market value of the housing unit minus estimated rental payments (for an extended discussion see Johnson, Renwick \& Short, 2010). We lack adequate data to fully estimate rental payments and market values of housing units back to 1967 . We therefore adopt a simpler approach. To estimate rental 
payments, we assume that people spend 30 percent of their household income on rent. This is a simplification of more complex HUD guidelines, but modeling the more complex HUD guidelines would require knowing more information than is available in the CPS all the way back to 1967 . We then estimate the value as the shelter portion of the threshold minus these estimated rental payments. When this simpler approach is executed in data where we have the actual SPM (2009 to 2012), we find that our approach leads to an overestimate of the impact of housing subsidies on poverty rates. We therefore examined the ratio of Censusestimated housing subsidy values to our subsidy values in each year and found them to be approximately 89 percent in all three years at the median. So we applied a correction factor of .89 to our estimated housing subsidy valuation in all years. This correction factor yielded much closer estimates of the impact of including housing subsidies on poverty rates in 2009 to 2012. Improving the historical estimation of housing subsidy valuation is an important area for future work.

\section{Taxes}

After-tax income is not available on the CPS files before 1979/1980. So we used NBER's Taxsim Program to calculate our after-tax estimates for earlier years. The starting point for our tax programs are Stata programs provided by NBER and created originally by Judith Scott-Clayton. We modify these for earlier years as income components that can go into the tax calculator begin falling off of the CPS or become combined with other categories of income in the CPS. We also made the simplifying assumption of using $\$ 0$ versus positive income in the determination of filing status (as compared to legal filing requirements) as we were not able to locate historical data on tax filing requirements. Since such data surely exists, this is an important area for potential improvement in our tax models in the future. We observed no major deviation in the distribution of our after-tax income variables, however, between 1978 and 1979.

NBER's Taxsim program only calculates state tax rates back to 1978. Prior to 1978, we estimated family state income tax liability after credits by multiplying the median share of state to federal tax liability for each state by each family's estimated federal tax liability. Prior to 1976, not all individual states are identifiable in the CPS and, instead, regional groupings or combinations of several states are provided. In these cases, we used the median tax rate for families in the combined region.

\section{MOOP}

Medical out-of-pocket expenses (MOOP) are imputed from the CEX to the CPS for all years. Based on work by Hutto et al., (2011), New York City CEO (2008) and Betson (2009), we use a hot-deck imputation strategy to calculate deciles of MOOP expenditures for consumer units in the CEX for 10 imputation groups, based on: number of elderly individuals in family $(0,1,2)$, an indicator for families of 1 , and poverty level (below 200 percent and $>=200$ percent FPL). The distribution of MOOP expenditures in each imputation group is preserved by randomly assigning deciles of expenditures to the same imputation groups in the CPS. Finally, total MOOP expenditures are then capped at $\$ 6,700$ per person (adjusted to nominal dollars using CPI-U), which is the 2011 Medicare 
Advantage Part D non-premium cap, per recommendations in Korenman and Remler (2012). This method indirectly imputes incidence for various demographic groups since deciles of $\$ 0$ in expenditures would remain in both datasets, but it does not force an exact percentage.

For 2011, the first year of overlap between MOOP expenditures asked in CPS and our imputed measure, our imputed estimate of MOOP estimates the overall median expenditures and the distribution fairly well, with some underestimation at the 95th and 99th percentiles of expenditures (see Table A1 below). However, using our capped, imputed MOOP as opposed to the CPS measure has a relatively minor impact on overall SPM poverty rates. A more comprehensive imputation measure would include health insurance status, but unfortunately that is not available in the CEX (unless premiums were paid for by the consumer unit).

We use the same CEX sample as we do for poverty thresholds (see above), which is a fiveyear moving sample from 1984 to 2012 with progressively fewer years of CEX data back to 1980, and then single-year estimates of MOOP expenditures for 1972/1973 and 1980. For the intermediate years 1974 to 1979 the decile expenditures were linearly interpolated. For 1967 to 1971, the same annual rate of change in the expenditures between 1972/1973 and 1980 was assumed and extrapolated to the earlier years.

\section{Child Care and Work Expenses}

Child care expenditures are imputed from the CEX to the CPS for all years. We utilize a two-step procedure to estimate child care expenditures based on earlier work in Hutto et al. (2011). We first use the CEX to predict the likelihood of using paid child care using the following covariates: number of children $(1,2,3+)$, number of adults in household $(1,2$, $3+$ ), poverty dummies ( $<100$ percent, 100 to 200 percent, and $>200$ percent FPL), head-offamily age ( $<25,25$ to 34,35 to 44,45 to 54,55 to $64,65+$ ), race (white, black, other), education of head (LTHS, HS, SC, BA-plus), family size, married, race*education interactions, race*age interaction, and a region indicator (Northeast, Midwest, South, West). We then apply these regression coefficients to the relevant CPS year and predict the likelihood of paid child care for each household. We constrain paid child care incidence in the CPS to match paid child care incidence in the CEX by number of adults present in the household $(1,2,3+)$.

After determining incidence, we used a hot-deck imputation strategy to assign deciles of child care expenditures to heads in the CPS based on: poverty level $(<100$ percent, 100 to 200 percent, and $>200$ percent FPL), number of children ( 1,2 and $>=3)$ and family status (married, unmarried, $3+$ adults). We use the same CEX sample and interpolation strategy as in the MOOP estimates (see above).

\section{Work Expenses}

Work expenses (e.g., commuting costs, uniforms, etc.) are estimated based on analyses of the Survey of Income and Program Participation (SIPP) provided by the Census Bureau. Using the SIPP, they estimate a median weekly value of work expenses from 1997 to 2012. We fix this value historically adjusting for CPI-U. Total work expenses for the consumer 
unit are then calculated as 85 percent of median work expense multiplied by the number of weeks worked, and summed for all workers above age 17 in the unit as per NAS panel recommendations. Child care expenditures and work expenses are combined and then capped so that their total does not exceed the reported earnings of the lowest earning spouse/ partner in the family.

Table A1

MOOP Distribution, 2011. CPS

\begin{tabular}{|c|c|c|c|c|c|c|}
\hline & \multicolumn{3}{|c|}{ Overall } & \multicolumn{3}{|c|}{ Families with 0 elderly } \\
\hline & Actual from CPS & Capped Imputation & Diff & Actual from CPS & Capped Imputation & Diff \\
\hline $1 \%$ & 0 & 0 & 0 & 0 & 0 & 0 \\
\hline $5 \%$ & 0 & 0 & 0 & 0 & 0 & 0 \\
\hline $10 \%$ & 0 & 0 & 0 & 50 & 0 & -50 \\
\hline $25 \%$ & 486 & 486 & 0 & 400 & 215 & -185 \\
\hline Mean & 3,437 & 3,142 & -295 & 3,544 & 2,688 & -856 \\
\hline $50 \%$ & 2,277 & 2,277 & 0 & 1,835 & 1,600 & -235 \\
\hline $75 \%$ & 5,104 & 4,976 & -128 & 4,750 & 4,005 & -745 \\
\hline $90 \%$ & 8,316 & 7,979 & -337 & 8,700 & 7,979 & -721 \\
\hline $95 \%$ & 14,110 & 11,071 & $-3,039$ & 12,168 & 11,071 & $-1,097$ \\
\hline \multirow[t]{3}{*}{$99 \%$} & 17,224 & 13,400 & $-3,824$ & 22,180 & 11,071 & $-11,109$ \\
\hline & \multicolumn{3}{|c|}{ Families with 1 elderly } & \multicolumn{3}{|c|}{ Families with $2+$ elderly } \\
\hline & Actual from CPS & Capped Imputation & Diff & Actual from CPS & Capped Imputation & Diff \\
\hline $1 \%$ & 0 & 0 & 0 & 0 & 1,025 & 1,025 \\
\hline $5 \%$ & 100 & 1,117 & 1,017 & 1,157 & 2,314 & 1,157 \\
\hline $10 \%$ & 480 & 1,158 & 678 & 2,314 & 2,360 & 46 \\
\hline $25 \%$ & 1,357 & 1,616 & 260 & 3,187 & 4,120 & 933 \\
\hline Mean & 4,153 & 3,870 & -282 & 7,250 & 6,932 & -318 \\
\hline $50 \%$ & 2,803 & 2,995 & 192 & 5,733 & 5,984 & 251 \\
\hline $75 \%$ & 5,260 & 5,225 & -35 & 9,194 & 9,836 & 642 \\
\hline $90 \%$ & 8,934 & 7,814 & $-1,119$ & 13,414 & 13,400 & -14 \\
\hline $95 \%$ & 12,237 & 10,937 & $-1,299$ & 16,514 & 13,400 & $-3,114$ \\
\hline $99 \%$ & 22,287 & 14,413 & $-7,874$ & 27,897 & 18,183 & $-9,714$ \\
\hline
\end{tabular}

\section{References}

Bailey, MJ.; Danziger, S., editors. Legacies of the War on Poverty. New York, NY: Russell Sage Foundation; 2013.

Bavier R. Reconciliation of income and consumption data in poverty measurement. Journal of Policy Analysis and Management. 2008; 27:40-62.

Bavier R. Recent trends in U.S. income and expenditure poverty. Journal of Policy Analysis and Management. 2014; 33:700-718.

Ben-Shalom, Y.; Moffitt, R.; Scholz, JK. An assessment of the effectiveness of anti-poverty programs in the United States. 2011. Available from: http://www.npc.umich.edu/publications/ working_papers/

J Policy Anal Manage. Author manuscript; available in PMC 2016 July 01. 
Betson, D.; Michael, R. Unpublished memorandum prepared for the Panel on Poverty and Family Assistance, Committee on National Statistics, National Research Council. Department of Economics, University of Notre Dame; 1993. A recommendation for the construction of equivalence scales.

Betson, D. Homeownership and poverty measurement; Paper presented at the Brookings/Census Bureau Conference on Improved Poverty Measurement; Washington, DC. October 20; 2009.

Bitler, M.; Hoynes, H. The more things change, the more they stay the same: The safety net, living arrangements, and poverty in the Great Recession; Paper presented at the NBER Conference on Labor Markets after the Great Recession; 2013.

Blank R. Evaluating Welfare Reform in the United States. Journal of Economic Literature. 2002; 40:1-43.

Blank RM. Presidential address: How to improve poverty measurement in the United States. Journal of Policy Analysis and Management. 2008; 27:233-254.

Blank R, Greenberg M. Improving the measurement of poverty. 2008:2008-17.The Hamilton Project, Discussion paper

Bohn, S.; Danielson, C.; Levin, M.; Mattingly, M.; Wimer, C. The California poverty measure: A new look at the social safety net. San Francisco, CA: Public Policy Institute of California; 2013.

Burkhauser RV. Deconstructing European poverty measures: What relative and absolute scales measure. Journal of Policy Analysis and Management. 2009; 28:715-725.

Cable, D. The Virginia poverty measure: An alternative poverty measure for the commonwealth. University of Virginia-Welden Cooper Center for Public Service, Demographics and Workforce Group; 2013.

Casper LM, Cohen PN, Simons T. How does POSSLQ measure up? Historical estimates of cohabitation. 1999U.S. Census Bureau Population Division Working Paper No. 36

Citro, C.; Michael, R., editors. Measuring poverty: A new approach. Washington D.C: National Academy Press; 1995.

Danziger S, Haveman R, Plotnick R. How income transfer programs affect work, savings, and the income distribution: A critical review. Journal of Economic Literature. 1981; 19:975-1028.

Engelhardt, GV.; Gruber, J. Social Security and the evolution of elderly poverty. In: Auerbach; Card; Quigley, editors. Public policy and the income distribution. New York, NY: Russell Sage; 2006.

Feenberg D, Coutts E. An introduction to the TAXSIM model. Journal of Policy Analysis and Management. 1993; 12:189-194.

Ganong, P.; Liebman, JB. The decline, rebound, and further rise in SNAP enrollment: Disentangling business cycle fluctuations and policy changes. Cambridge, MA: National Bureau of Economic Research; 2013. NBER Working Paper No. w19363

Garfinkel, I.; Rainwater, L.; Smeeding, T. Wealth and welfare states? Is America a laggard or leader?. New York, NY: Oxford University Press; 2010.

Grogger J. Welfare transitions in the 1990s: The economy, welfare policy, and the EITC. Journal of Policy Analysis and Management. 2004; 23:671-695.

Hahn, H.; Isaacs, JB.; Rennae, S.; Steuerle, CE.; Vericker, T. Kids' share 2011: Report on federal expenditures on children through 2010. Washington, D.C.: Joint Brookings and Urban Institute Research Report; 2011.

Hoynes, HW. The earned income tax credit, welfare reform, and the employment of low skill single mothers. In: Toussaint-Comeau, M.; Meyer, BD., editors. Strategies for improving economic mobility of workers: Bridging research and practice. Kalamazoo, MI: Upjohn Press; 2009.

Hoynes HW. Comment on Meyer and Sullivan. Brookings Papers on Economic Activity (Fall). 2012:184-189.

Hutto N, Waldfogel J, Kaushal N, Garfinkel I. Improving the measurement of poverty. Social Service Review. 2011; 35:39-74. [PubMed: 26316658]

Moffitt R. Incentive effects of the U.S. welfare system: A review. Journal of Economic Literature. 1992; 30:1-61.

Nolan B, Whelan CT. Using non-monetary deprivation indicators to analyze poverty and social exclusion: Lessons from Europe? Journal of Policy Analysis and Management. 2010; 29:305-325. 
NYC Center for Economic Opportunity. The CEO poverty measure. 2008. Working paper, August, CEO, New York, NYAvailable from http://www.nyc.gov/html/ceo/downloads/pdf/

final_poverty_report.pdf

NYC Center for Economic Opportunity. The CEO poverty measure 2005-2011: An annual report by the NYC Center for Economic Opportunity. 2013. Available from http://www.nyc.gov/html/ceo/ downloads/pdf/ceo_poverty_measure_2005_2011.pdf

Renwick, T. Geographic adjustments of supplemental poverty measure thresholds: Using the American Community Survey five-year data on housing costs. U.S. Census Bureau; 2011. SEHSD Working Paper Number 2011-21

Short K. The research supplemental poverty measure: 2010. Current Population Reports. 2011:P60241.

Short K. The research supplemental poverty measure: 2011. Current Population Reports. 2012:P60_ 244.

Short K. The research supplemental poverty measure: 2012. Current Population Reports. 2013:P60247.

Short, K.; Donahue, D.; Lynch, G. EITC estimates in the CPS ASEC simulations of after-tax income: Hispanic population. Workshop of the National Association for Welfare Research and Statistics; 2012.

Smeeding TM. The antipoverty effectiveness of in-kind transfers. Journal of Human Resources. 1977; 12:360-378. [PubMed: 925348]

Smeeding TM. New comparative measures of income, material deprivation, and well-being. Journal of Policy Analysis and Management. 2009; 28:745-752.

Smeeding, TM.; Isaacs, JB.; Thornton, KA. Wisconsin poverty report: Is the safety net still protecting families from poverty in 2011?. University of Wisconsin-Madison, Institute for Research on Poverty; 2013.

Smeeding T, Waldfogel J. Fighting poverty: Attentive policy can make a huge difference. Journal of Policy Analysis and Management. 2010; 29:401-407.

Wheaton, L. Underreporting of means-tested transfer programs in the CPS and SIPP. Washington, DC: The Urban Institute; 2008.

Wheaton, L.; Giannarelli, L.; Martinez-Schiferl, M.; Zedlewski, S. How do states' safety net policies affect poverty?. Urban Institute; 2011. Working Families Paper 19

Wimer C, Fox L, Garfinkel G, Kaushal N, Waldfogel J. Trends in poverty with an anchored supplemental poverty measure. Columbia Population Research Center Working Paper. 2013a

Wimer, C.; Garfinkel, I.; Gelblum, M.; Blanco, NL.; Si, Y.; Teitler, J.; Waldfogel, J. Income poverty and material hardship in New York City: Evidence from a new household survey; Presented at the Population Association of America Annual Meeting; May 2013; $2013 \mathrm{~b}$.

Zedlewski S, Giannarelli L, Wheaton L. Estimating the potential effects of poverty reduction policies. Journal of Policy Analysis and Management. 2010; 29:387-400. 


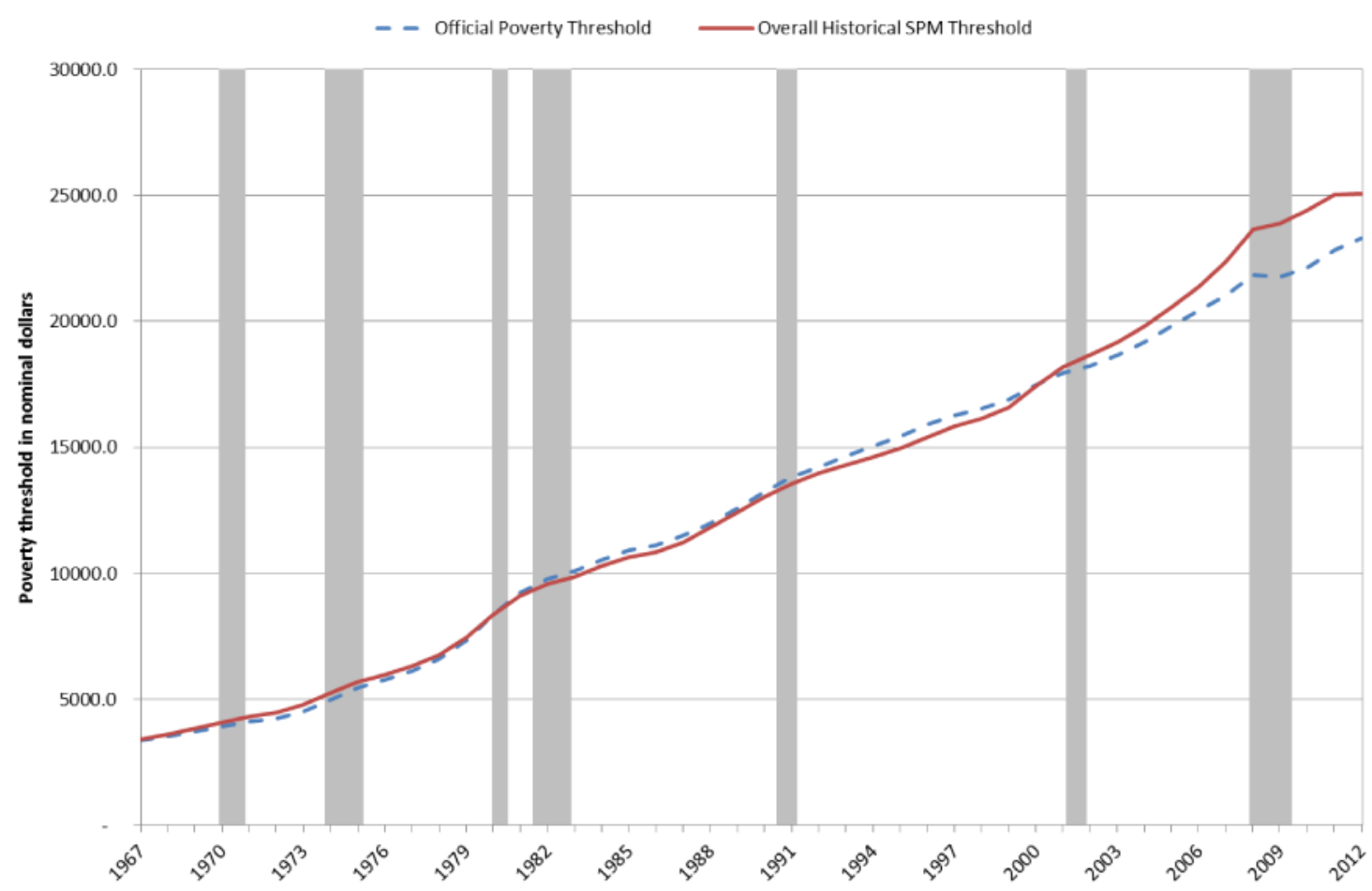

Note: Thresholds based on two -child households. Shaded bars are recessions as defined by NBER.

Figure 1.

Historical Poverty Threshold Comparison, 1967-2012 
- - OPM - Historical SPM

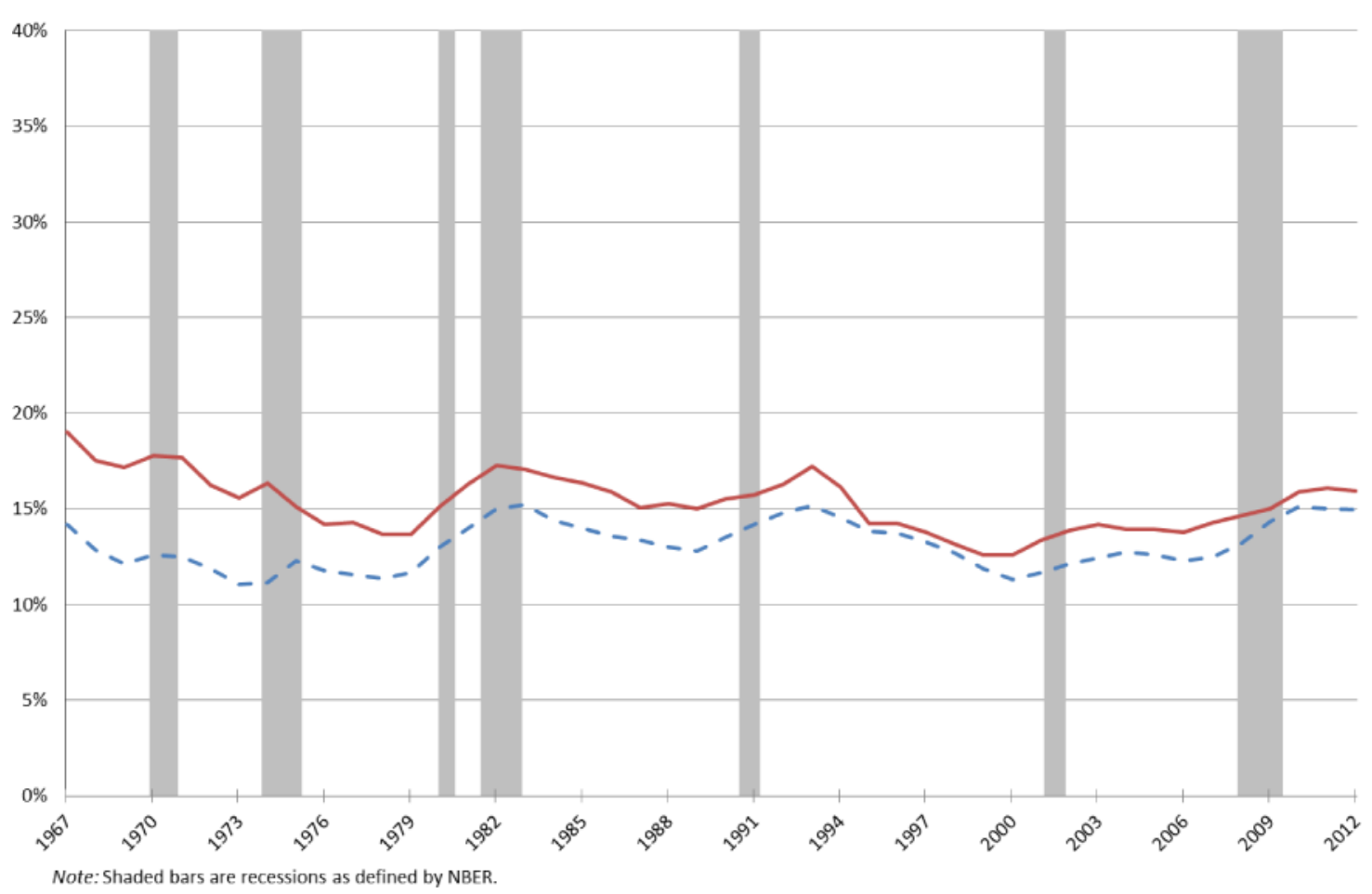

Figure 2.

Official vs Historical Supplemental Overall Poverty Rates, 1967-2012 
- Impact of Transfers (OPM)

- Impact of Transfers (Historical SPM)

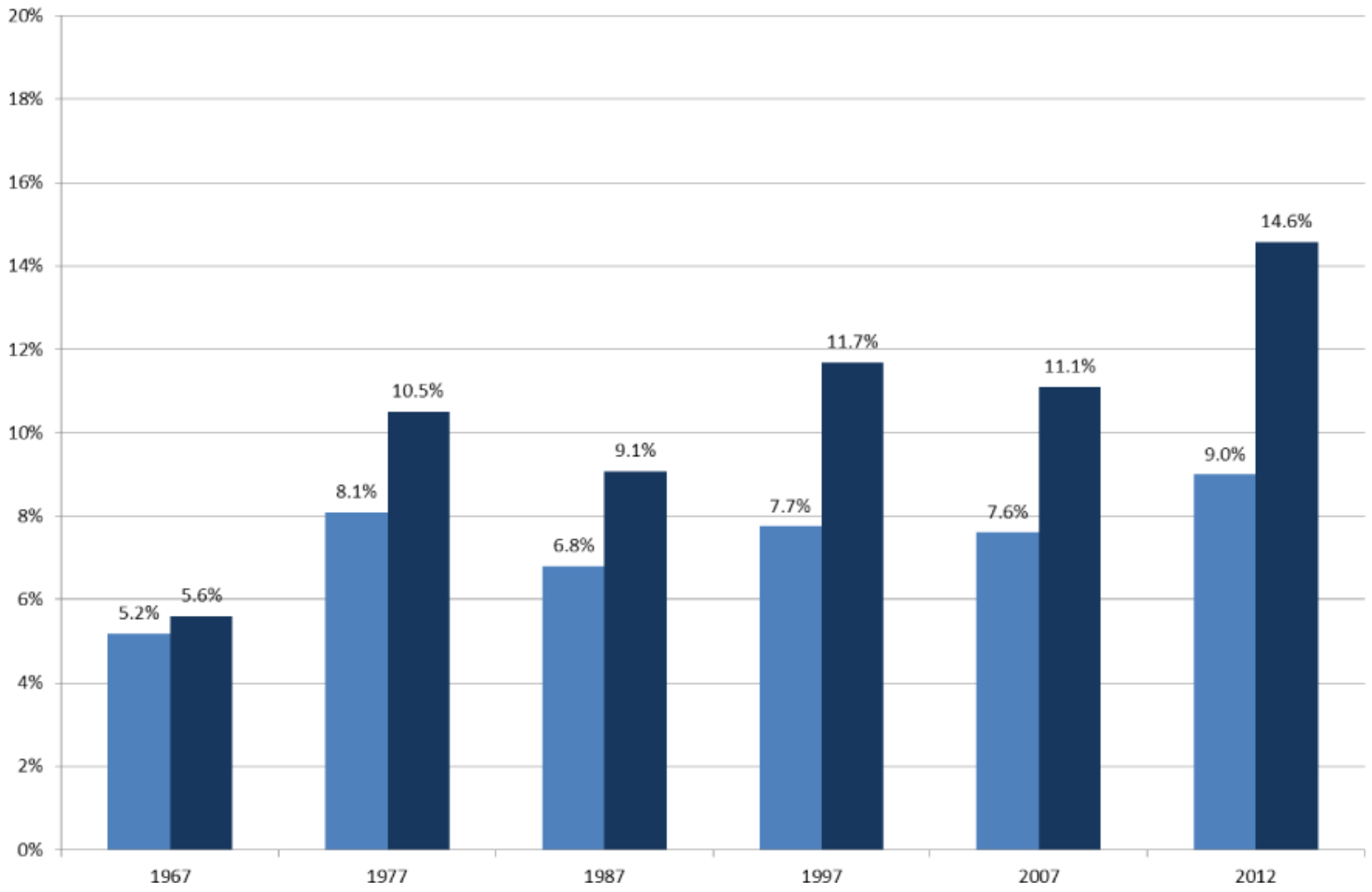

Figure 3 .

Percentage Point Impact of Transfers Under OPM and Historical SPM, 1967-2012 


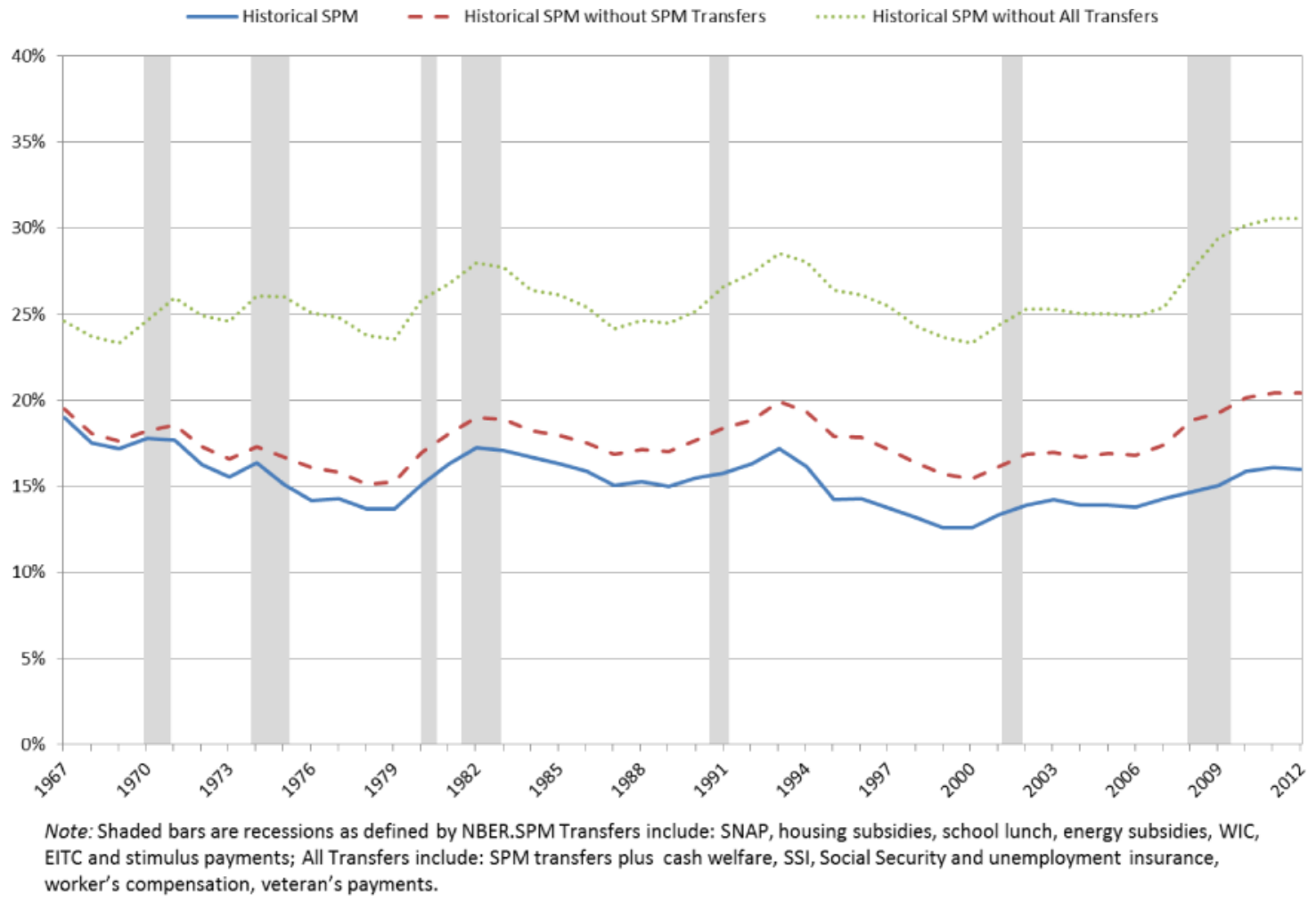

Figure 4a.

Overall Poverty, with and without SPM and Total Transfers, 1967-2012 


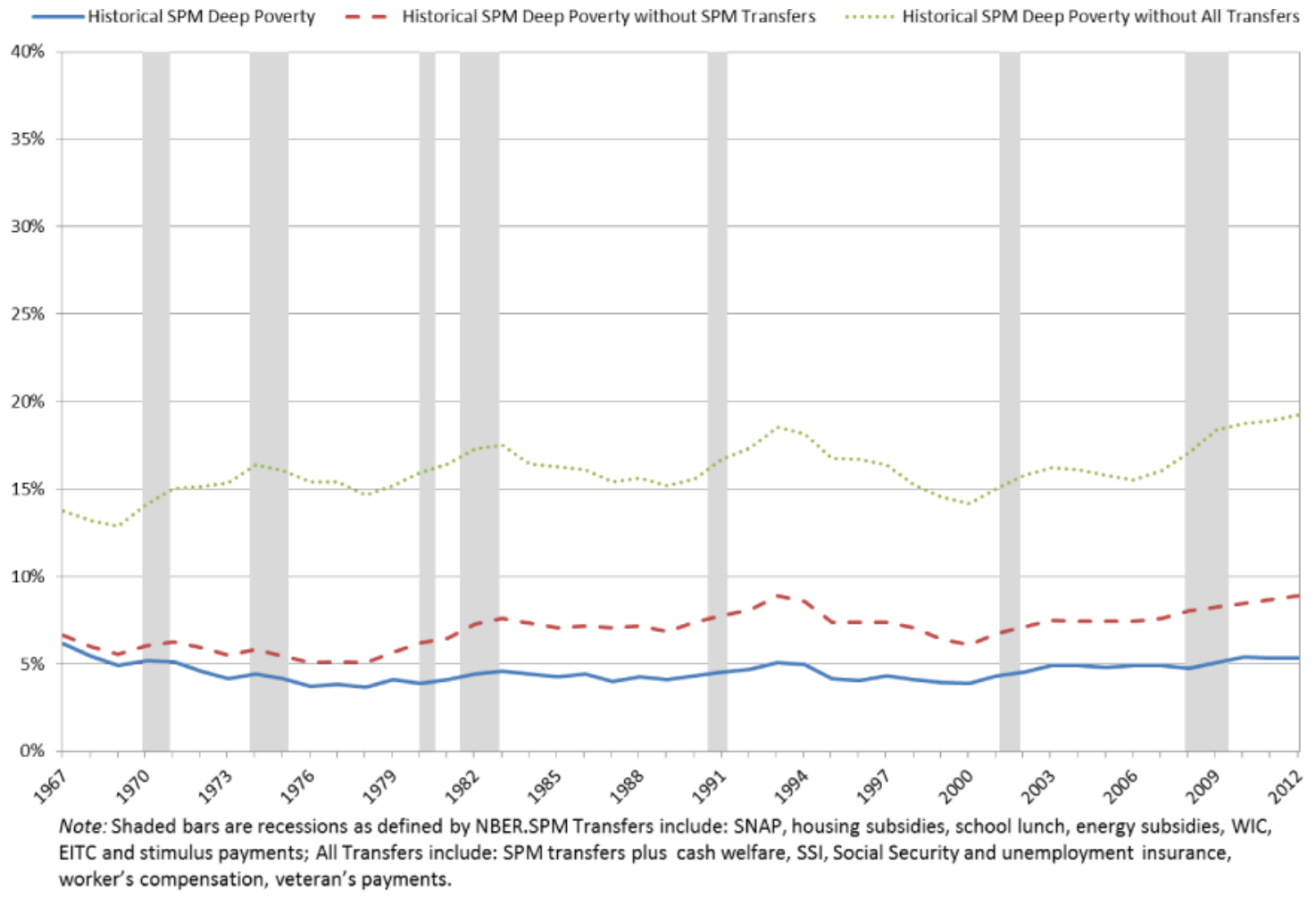

Figure 4b.

Overall Deep Poverty, with and without SPM and Total Transfers, 1967-2012 
- - OPM-Under $18 \longrightarrow$ Historical SPM-Under 18

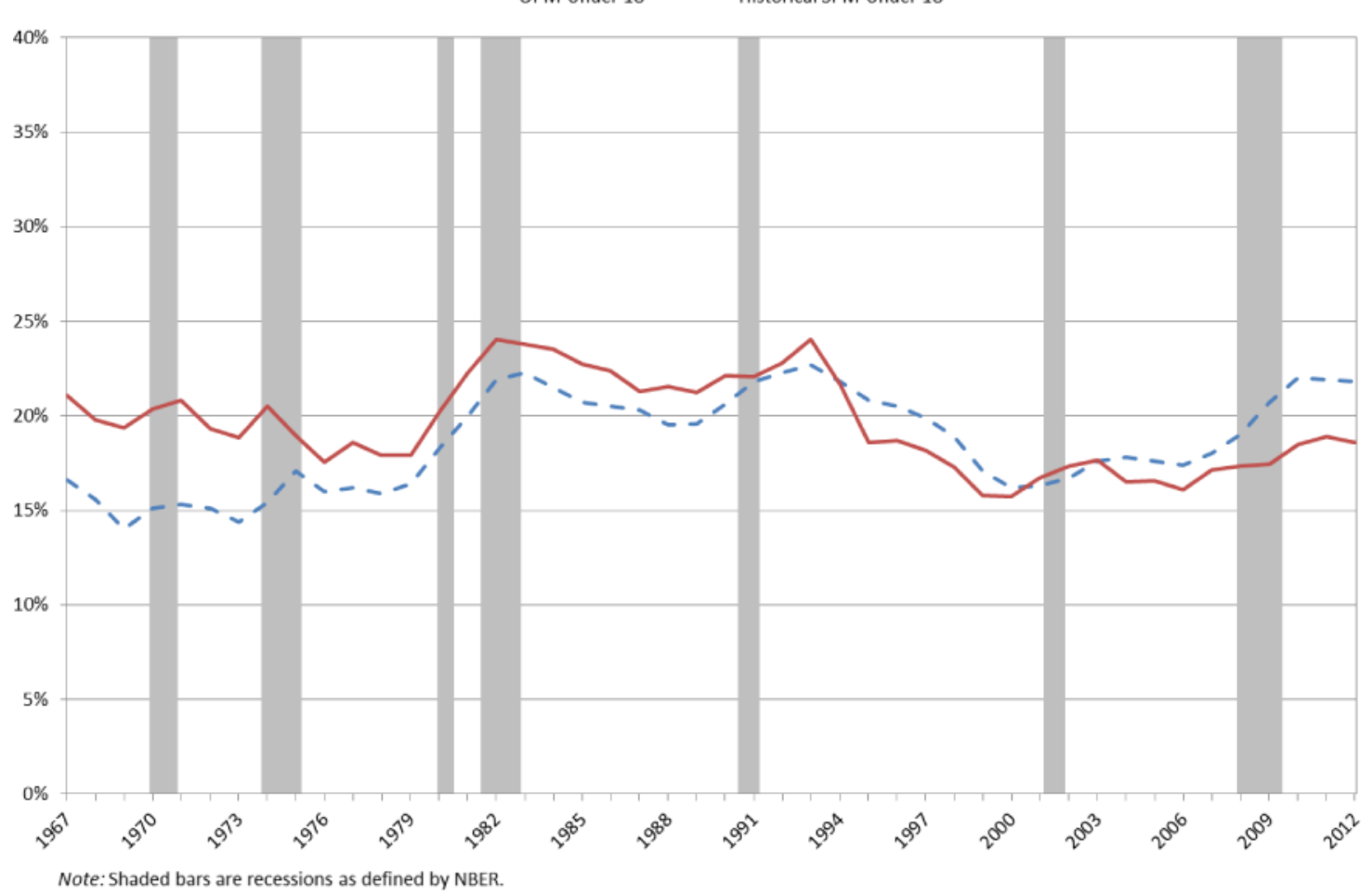

Figure 5.

Child Poverty Trends, 1967-2012 


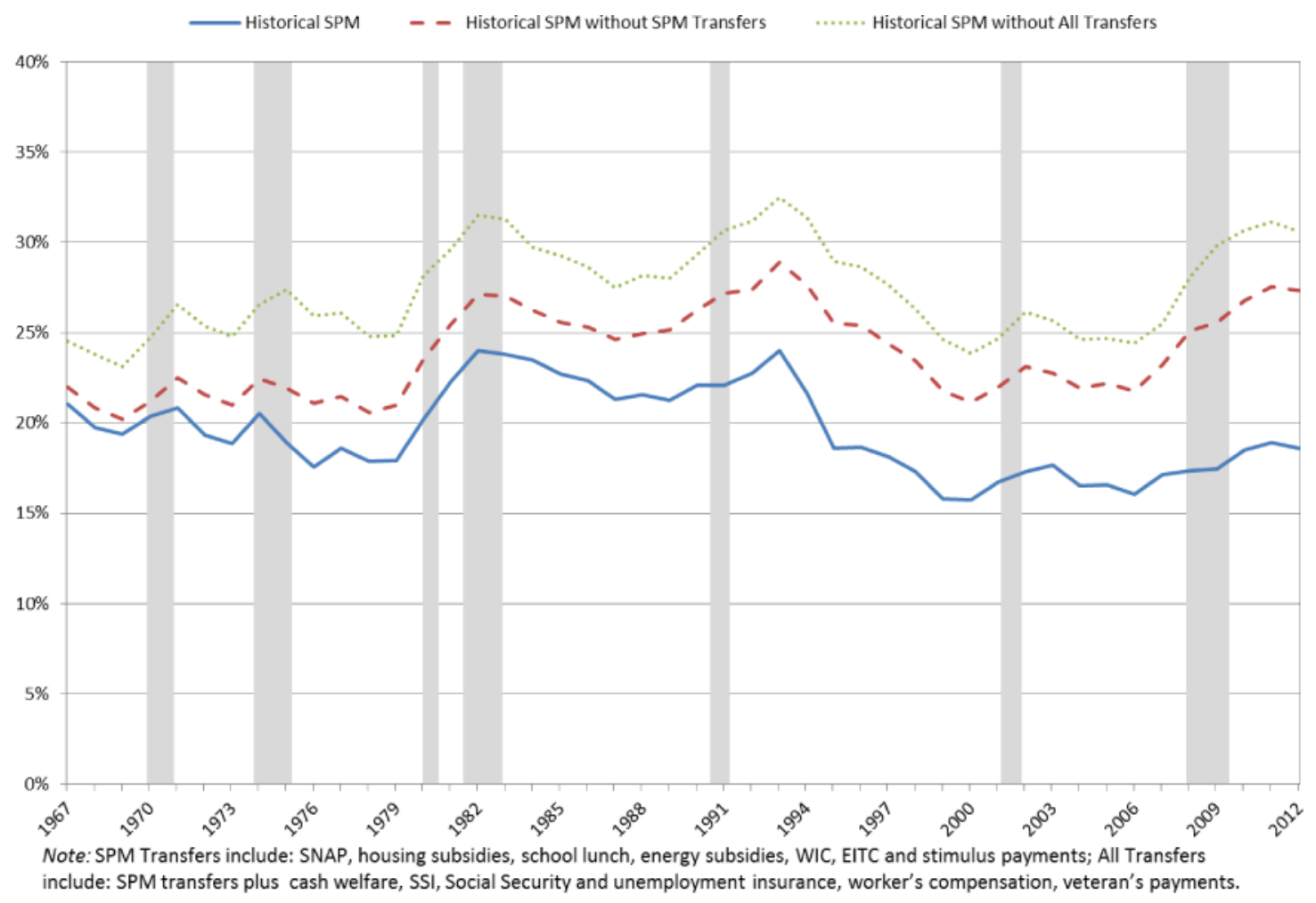

Figure 6a.

Child Poverty, with and without SPM and Total Transfers, 1967-2012 


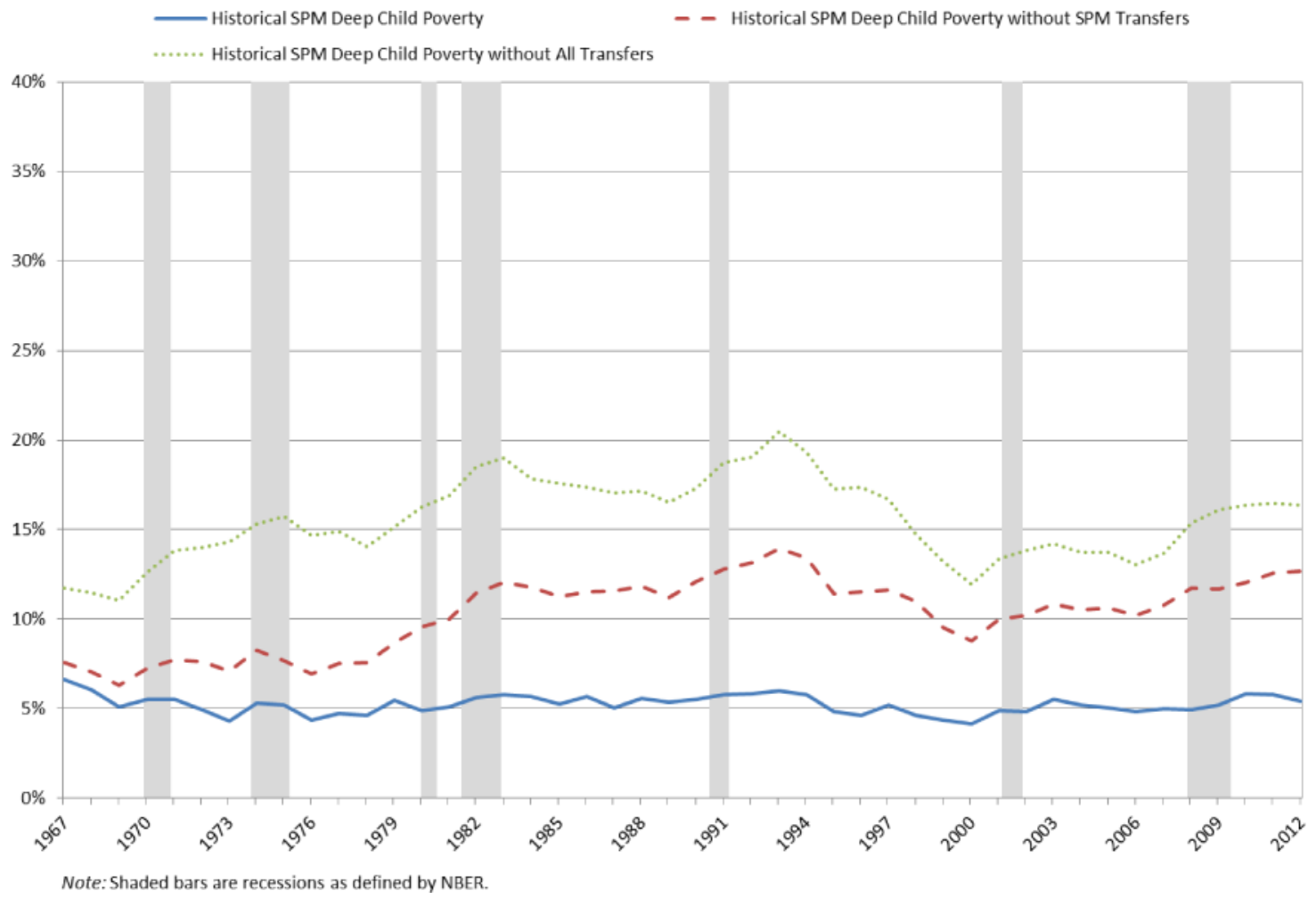

Figure 6b.

Child Deep Poverty, with and without SPM and Total Transfers, 1967-2012 


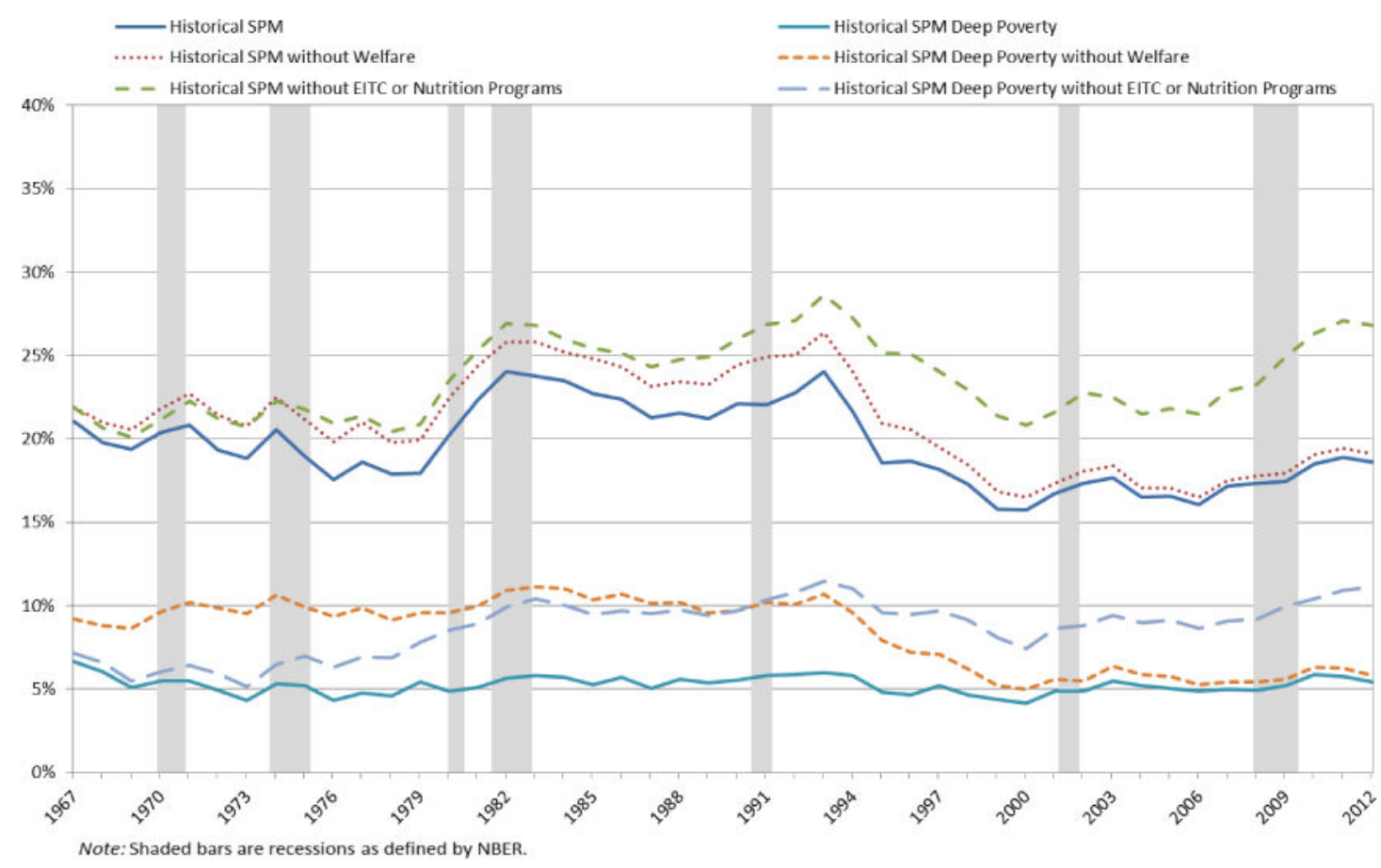

Figure 7.

Individual Impact of EITC and Welfare on Child Poverty and Child Deep Poverty, 19672012

J Policy Anal Manage. Author manuscript; available in PMC 2016 July 01. 
- - OPM-65+ — Historical SPM-65+

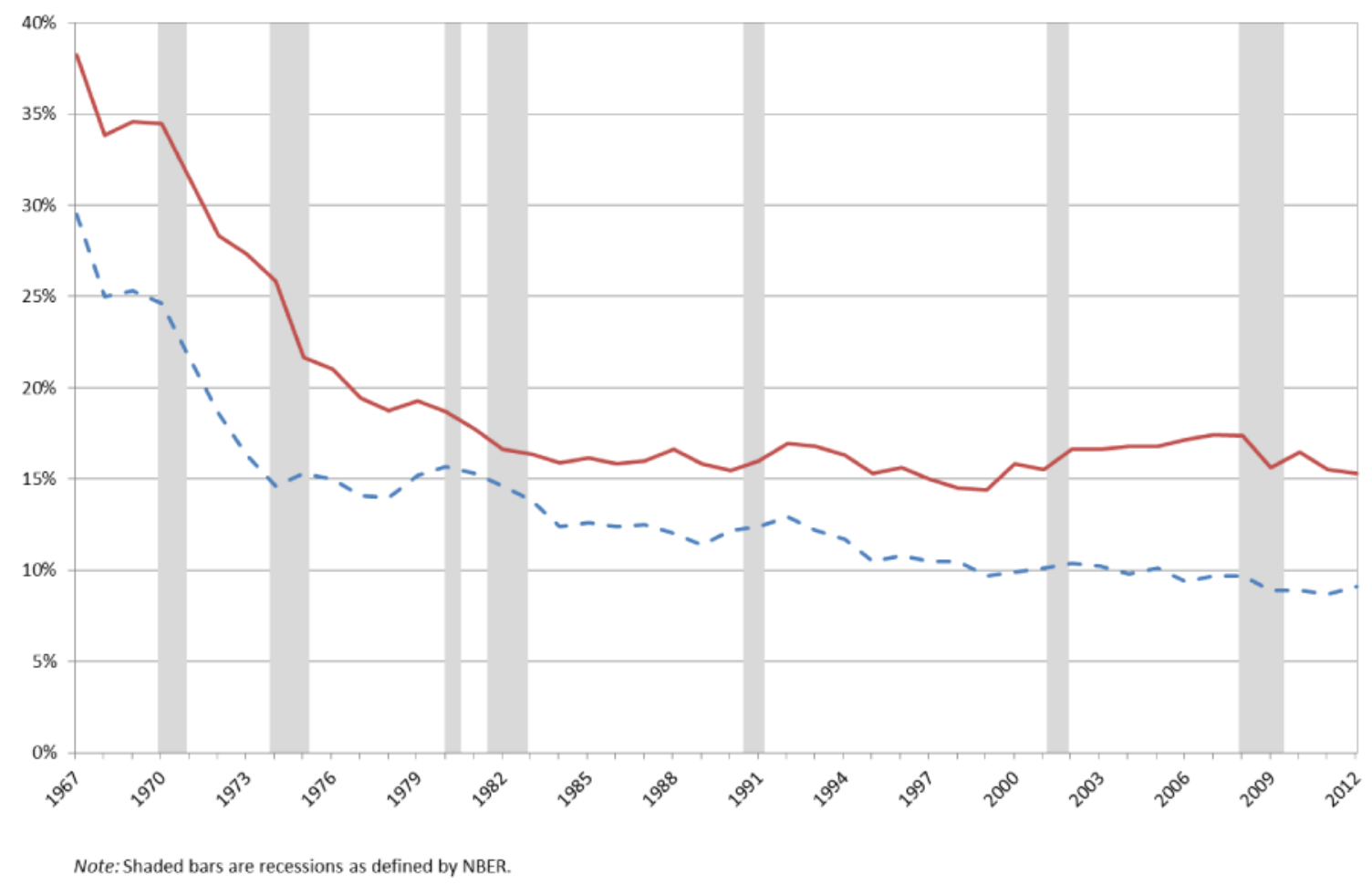

Figure 8.

Elderly Poverty, 1967-2012 
Table 1

Comparison of OPM, SPM and Historical SPM.

\begin{tabular}{|c|c|c|c|}
\hline & $\begin{array}{l}\text { Official Poverty Measure } \\
\text { (OPM) }\end{array}$ & $\begin{array}{l}\text { Supplemental Poverty } \\
\text { Measure (SPM) }\end{array}$ & $\begin{array}{l}\text { Historical Supplemental Poverty } \\
\text { Measure (Historical SPM) }\end{array}$ \\
\hline Family/Poverty Unit Definition & $\begin{array}{l}\text { Family: } \\
\text { Related by } \\
\text { Blood, } \\
\text { Marriage or } \\
\text { Adoption }\end{array}$ & 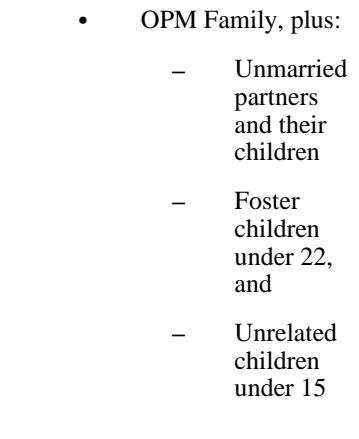 & $\begin{aligned} &-\quad \text { OPM Family, plus: } \\
&-\quad \begin{array}{l}\text { Unmarried partners } \\
\text { and their children } \\
\text { (identified using } \\
\text { adjusted POSSLQ } \\
\text { method before } \\
1995 \text { ) }\end{array} \\
&-\quad \begin{array}{l}\text { Foster children } \\
\text { under 22 } \\
\text { (unidentified before } \\
1988 \text { ) }\end{array} \\
&-\quad \begin{array}{l}\text { Unrelated children } \\
\text { under 15 }\end{array}\end{aligned}$ \\
\hline Poverty Thresholds & $\begin{array}{l}\text { Minimal food } \\
\text { diet costs in } \\
1963 \\
\text { multiplied by } \\
\text { three, updated } \\
\text { for inflation, } \\
\text { primarily by } \\
\text { the CPI-U } \\
\text { V } \\
\text { Vary by family } \\
\text { size and } \\
\text { structure, and } \\
\text { also age of } \\
\text { household head } \\
\text { (above or } \\
\text { below age 65) }\end{array}$ & 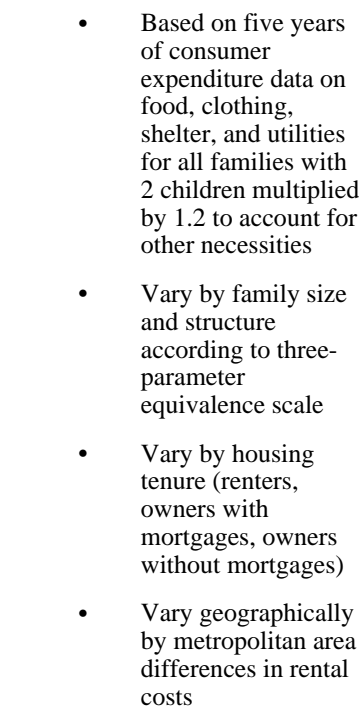 & $\begin{array}{l}\text { - Based on five years of } \\
\text { consumer expenditure data } \\
\text { on food, clothing, shelter, } \\
\text { and utilities for all families } \\
\text { with } 2 \text { children multiplied } \\
\text { by } 1.2 \text { to account for other } \\
\text { necessities } \\
\text { - Vary by family size and } \\
\text { structure according to three- } \\
\text { parameter equivalence scale } \\
\text { - Vary by housing tenure } \\
\text { (renters, owners with } \\
\text { mortgages, owners without } \\
\text { mortgages); mortgage status } \\
\text { imputed all years, ownership } \\
\text { status imputed prior to } 1975 \\
\text { - } \quad \begin{array}{l}\text { Do not vary geographically } \\
\text { by metropolitan area } \\
\text { differences in rental costs }\end{array} \\
\text { Based on fewer than } 5 \text { years } \\
\text { of data prior to } 1984\end{array}$ \\
\hline Resources & $\begin{array}{l}\text { Pretax Money } \\
\text { (cash) Income } \\
\text { including cash } \\
\text { welfare, SSI, } \\
\text { Social } \\
\text { Security, } \\
\text { unemployment } \\
\text { insurance, } \\
\text { worker's } \\
\text { compensation, } \\
\text { and veteran's } \\
\text { payments }\end{array}$ & $\begin{aligned} & \text { - OPM cash income, } \\
& \text { plus: } \\
&-\quad \text { In-kind } \\
& \text { benefits } \\
& \text { (SNAP, } \\
& \text { School } \\
& \text { Lunch, } \\
& \text { WIC, } \\
& \text { Housing } \\
& \text { Subsidies, } \\
& \text { and } \\
& \text { LIHEAP) } \\
&-\quad \text { Minus } \\
& \text { income } \\
& \text { taxes and } \\
& \text { plus } \\
& \text { income tax } \\
& \text { credits } \\
& \text { - } \\
& \text { Minus } \\
& \text { medical } \\
& \text { expenses, }\end{aligned}$ & $\begin{aligned} & \text { - } \text { OPM cash income, plus: } \\
&-\quad \text { In-kind benefits } \\
& \text { (SNAP, School } \text { Lunch, WIC, } \\
& \text { Housing Subsidies, } \text { and LIHEAP) } \\
&-\quad \text { Minus income } \\
& \text { taxes and plus } \\
& \text { income tax credits } \\
&-\quad \text { Minus medical and } \\
& \text { work/child care } \\
& \text { expenses } \\
& \text { Includes following } \\
& \text { imputations: } \\
& \quad \text { Housing } \\
& \text { subsidies } \\
& \text { prior to } \\
& 1975, \\
& \text { Taxes, } \\
& \text { SNAP and }\end{aligned}$ \\
\hline
\end{tabular}




\begin{tabular}{|c|c|c|c|}
\hline & $\begin{array}{l}\text { Official Poverty Measure } \\
\text { (OPM) }\end{array}$ & $\begin{array}{l}\text { Supplemental Poverty } \\
\text { Measure (SPM) }\end{array}$ & $\begin{array}{l}\text { Historical Supplemental Poverty } \\
\text { Measure (Historical SPM) }\end{array}$ \\
\hline 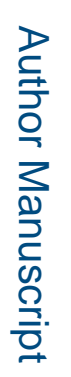 & & $\begin{array}{ll}\text { work/child } \\
\text { care } \\
\text { expenses, } \\
\text { and child } \\
\text { support } \\
\text { paid }\end{array}$ & $\begin{array}{ll}\text { School } \\
\text { Lunch } \\
\text { prior to } \\
\text { 1979, } \\
\text { WIC prior } \\
\text { to 2001, } \\
\text { and } \\
\text { Medical } \\
\text { and child } \\
\text { care } \\
\text { expenses } \\
\text { for all } \\
\text { years }\end{array}$ \\
\hline
\end{tabular}

Notes: As described in text, the following abbreviations are used in this table: POSSLQ-Partners of opposite sex sharing living quarters; CPI-UConsumer Price Index for Urban Consumers; SNAP-Supplemental Nutrition Assistance Program (formerly food stamps); WIC-Special Supplemental Nutrition Program for Women, Infants, and Children; LIHEAP- Low-Income Home Energy Assistance Program; SSI-Supplemental Security Income. 